\title{
Consensus statement for stability assessment and reporting for perovskite photovoltaics based on ISOS procedures
}

\author{
Mark V. Khenkin ${ }^{1,2}$, Eugene A. Katz ${ }^{1,3 \star}{ }^{\text {, Antonio Abate }}{ }^{4}$, Giorgio Bardizza5 , Joseph J. Berry ${ }^{6}{ }^{6}$, \\ Christoph Brabec ${ }^{7,8}$, Francesca Brunetti ${ }^{9}$, Vladimir Bulović ${ }^{10}$, Quinn Burlingame ${ }^{11}$, Aldo Di Carlo ${ }^{9}$, \\ Rongrong Cheacharoen ${ }^{12}$, Yi-Bing Cheng ${ }^{13}$, Alexander Colsmann ${ }^{10}{ }^{14}$, Stephane Cros ${ }^{15}$, \\ Konrad Domanski ${ }^{16}{ }^{16}$ Michał Dusza ${ }^{17}$, Christopher J. Fell ${ }^{18}$, Stephen R. Forrest ${ }^{19,20,21}$, \\ Yulia Galagan (1) 22, Diego Di Girolamo9,23, Michael Grätzel ${ }^{24}$, Anders Hagfeldt ${ }^{25}$, Elizabeth von Hauff ${ }^{26}$, \\ Harald Hoppe ${ }^{27}$, Jeff Kettle ${ }^{28}$, Hans Köbler ${ }^{4}$, Marina S. Leite ${ }^{29,30}$, Shengzhong (Frank) Liu ${ }^{31,32}$, \\ Yueh-Lin Loo ${ }^{11,33}$, Joseph M. Luther ${ }^{6}$, Chang-Qi Ma ${ }^{34}$, Morten Madsen $\mathbb{1}^{35}$, Matthieu Manceau' \\ Muriel Matheron ${ }^{15}$, Michael McGehee ${ }^{6,36}$, Rico Meitzner ${ }^{27}$, Mohammad Khaja Nazeeruddin ${ }^{37}$, \\ Ana Flavia Nogueira $\mathbb{B}^{38}$, Çağla Odabașı $\mathbb{1}^{39}{ }^{3}$, Anna Osherov ${ }^{10}$, Nam-Gyu Park ${ }^{40}$, Matthew O. Reese ${ }^{6}$, \\ Francesca De Rossi ${ }^{9,41}$, Michael Saliba $\mathbb{1}^{42,43}$, Ulrich S. Schubert $\mathbb{D}^{27,44}$, Henry J. Snaith ${ }^{45}$, \\ Samuel D. Stranks ${ }^{46}$, Wolfgang Tress $\mathbb{B D}^{25}$, Pavel A. Troshin ${ }^{47,48}$, Vida Turkovic ${ }^{35}$, Sjoerd Veenstra ${ }^{22}$, \\ Iris Visoly-Fisher ${ }^{1,3}$, Aron Walsh $\mathbb{1}^{49,50}$, Trystan Watson ${ }^{41}$, Haibing Xie ${ }^{51}$, Ramazan Yıldırım $\mathbb{1}^{39}$, \\ Shaik Mohammed Zakeeruddin ${ }^{24}$, Kai Zhu ${ }^{6}$ and Monica Lira-Cantu ${ }^{51 \star}$
}

Improving the long-term stability of perovskite solar cells is critical to the deployment of this technology. Despite the great emphasis laid on stability-related investigations, publications lack consistency in experimental procedures and parameters reported. It is therefore challenging to reproduce and compare results and thereby develop a deep understanding of degradation mechanisms. Here, we report a consensus between researchers in the field on procedures for testing perovskite solar cell stability, which are based on the International Summit on Organic Photovoltaic Stability (ISOS) protocols. We propose additional procedures to account for properties specific to PSCs such as ion redistribution under electric fields, reversible degradation and to distinguish ambient-induced degradation from other stress factors. These protocols are not intended as a replacement of the existing qualification standards, but rather they aim to unify the stability assessment and to understand failure modes. Finally, we identify key procedural information which we suggest reporting in publications to improve reproducibility and enable large data set analysis.

o ensure economic feasibility and competitive levelized cost of electricity, new photovoltaic (PV) technologies must offer long-term stability alongside high power conversion efficiency (PCE). For instance, the lifetime expectation for a PV module in a power plant is $20-25$ years, to match the reliability of silicon-wafer-based modules. At present, the long-term stability of emerging technologies such as organic photovoltaic (OPV) cells, dye-sensitized solar cells (DSSCs) and halide perovskite solar cells (PSCs) is not meeting this target and improvements are hampered by a lack of understanding of the module failure modes.

The existing qualification tests described in the International Electrotechnical Commission (IEC) standards on terrestrial PV modules (such as IEC 61215) ) $^{1-3}$ are designed for the field performance of silicon panels to screen for well-understood degradation modes generally associated with issues at the module level. These tests, however, are unlikely to be well-suited to OPV cells, DSSCs and PSCs because of their fundamentally different material properties and device architectures. In fact, various reports have shown that the stability of these devices cannot be fully assessed by the procedures developed for conventional PV products ${ }^{4-10}$, which led to the publication of various studies that attempted to understand the degradation mechanisms in emerging PV systems. Unfortunately, these studies lacked consistency in the assessment and reporting procedures, which prevented data comparison and, consequently, the identification of various degradation factors and failure mechanisms.

In light of such shortcomings, in 2011, a broad consortium of researchers developed recommendations for evaluating the stability of OPV cells ${ }^{11}$. These standardized ageing experiments (the socalled ISOS protocols) were established at the International Summit on Organic PV Stability (ISOS) held in Roskilde, Denmark, in 2010. They outline a consensus between researchers in the OPV field on performing and reporting degradation studies in a controlled and reproducible way. These protocols are not intended to be a standard qualification test, nor are they suited for application by industry or insurance agencies; however, it is worth mentioning that tests based on the ISOS protocols were recently considered at the IEC level 
(see IEC TS 62876-2-1 ${ }^{3}$ ). Unlike IEC qualification standards, a solar cell cannot pass or fail ISOS stability tests. Instead, ISOS protocols are intended primarily for lab-scale devices and aim to ensure the comparability of PV testing performed at different laboratories, enabling successful round-robin experiments ${ }^{12-14}$, and to assist in improving the quality and relevance of published data. This approach has subsequently allowed a more comprehensive understanding of device degradation. While these protocols are most frequently applied at the cell level, their application to neat materials, 'half' cells (incomplete PV stacks) and mini modules can also provide valuable information on degradation processes.

PSCs are among the most promising emerging PV technologies, especially when used in high-efficiency multi-junction architectures. The PCE of these potentially inexpensive, solution-processable devices has grown tremendously over the past decade, reaching over $25 \%$ in a single junction PSC and $28 \%$ in a perovskite-on-silicon tandem ${ }^{15,16}$. The next major challenge for PSC technology, along with large-area processing and manufacturing upscaling, is improving their reliability.

PSC degradation is affected by multiple parameters whose impact on device stability is still not fully understood or appreciated by IEC standards. These parameters include exposure to visible ${ }^{17}$ and ultraviolet (UV) light $^{18}$, high temperature ${ }^{19-21}$, contamination from the ambient environment (oxygen, humidity) $22-24$ and electrical bias ${ }^{4,25,26}$. Stability studies for PSCs are drawing increasing attention but, despite the already large number of publications, it is difficult to compare the available results, mostly because of differences in the control and reporting of parameters and the inconsistent application of statistics to stability data ${ }^{27}$. The development of unified PSC stability evaluation procedures by the research community, similar to the procedures recently developed for PSC efficiency measurements $\mathrm{s}^{28-31}$, is therefore a priority ${ }^{4-10,27,32,33}$. Given the analogy to the OPV case, ISOS protocols are an excellent starting point for unifying PSC stability testing, provided that they are adapted to address the following particularities of PSCs: recovery processes after stress removal; the presence of mobile charged species (ions); and differentiation between the processes related to exposure to the ambient atmosphere from intrinsic device-related factors. PSCs are also known to exhibit hysteresis in their current density-voltage $(J-V)$ characteristics (that is, the $J-V$ measurements depend on the direction and rate of the voltage sweep ${ }^{34,35}$ ). This imposes constraints on cell performance and stability assessment, but does not necessarily signify less stable devices ${ }^{36}$.

During the 11th International Summit on Organic and Hybrid Photovoltaics Stability held in October 2018 in Suzhou, China, a discussion panel involving many researchers working on PSCs laid the groundwork for the development of procedures for testing and reporting PSC stability, which are presented in this Consensus Statement. First, we discuss the suitability of existing ISOS stress protocols designed for OPV cells to understand degradation pathways in PSCs. Second, we propose additional stress tests to account for factors that detrimentally affect the stability of PSCs, such as electrical bias and light-dark cycling. Additionally, to discriminate the impact on device stability of intrinsic factors from extrinsic ones, we suggest a subset of tests to be conducted under inert atmosphere. Next, we identify key technical and procedural information about stability testing that should be reported in publications to improve transparency and reproducibility in the field. We also discuss the use of figures-of-merit for device stability in light of the various PCE evolutions reported for PSCs. Finally, we envision that improvements in consistency of stability testing and reporting by adopting the unified set of protocols and reporting recommendations proposed will enable the consolidation of a large volume of data published in the future into a single database that could, in turn, be used to reliably compare stability studies, to analyze the relative significance of various degradation factors and to ultimately identify key failure mechanisms in devices.

\section{Existing ISOS stability protocols}

ISOS protocols designed for OPV cells, which are reported in detail elsewhere $^{11}$, are grouped in terms of the applied stresses into five categories, shelf-life or dark storage testing, outdoor testing, light soaking testing, thermal cycling testing and light-humidity-thermal cycling testing, all of which are also highly relevant to PSCs as discussed below. Each category has three levels of sophistication, basic, intermediate and advanced, the goal of which is to cover different levels of laboratory infrastructure. The first, basic level (level 1) requires only commonly available equipment and provides relatively low control over the stress factors. While limited insights into the PSC degradation can be gathered from these tests, we suggest such first-level procedures as the minimum requirement for stability testing. The second and third levels of sophistication (intermediate and advanced, level 2 and 3, respectively) require more specialized tools, such as environmental chambers and maximum power point (MPP) trackers, but provide higher levels of confidence in the results and, in most cases, more stringent test conditions. The protocols can be applied to both encapsulated and unencapsulated devices provided it is clearly reported (see the detailed discussion below in 'Intrinsic stability testing (ISOS-I)'). Stress tests specific to encapsulated modules (including hail tests, potential-induced degradation, bypass diode stability and so on $^{1,2}$ ), as well as mechanical stability and special consideration for space applications, are outside the scope of this report, and indeed will likely be leveraged from the existing IEC 61215 standard.

Dark storage studies (ISOS-D) provide information on the tolerance of the solar cells to oxygen, moisture, other aggressive atmospheric components naturally present in air (for example, $\mathrm{CO}_{2}$, $\mathrm{NO}_{x}, \mathrm{H}_{2} \mathrm{~S}$ ), and elevated temperatures. In other words, ISOS-D tests estimate a cell's shelf life under ambient conditions when it is not exposed to light. The ambient atmosphere plays a crucial role in determining the lifetime of perovskite absorbers and of some of the transport layers used in PSC architectures ${ }^{23,37,38}$. In particular, interaction with ambient species can promote the formation of traps ${ }^{39}$ or charge carrier barriers ${ }^{40}$ (as a result of increased density of mobile defects or ions and electronic traps within the active layer) as well as perovskite decomposition, which quickly deteriorate device performance ${ }^{22}$. Atmospheric species were also shown to charge the perovskite surface, affecting the ion distribution across the device ${ }^{41}$. The impact of these factors is taken into consideration in the ISOS-D-1 tests, where the cell environment is monitored but not explicitly controlled (room temperature in the laboratory is assumed to be $23 \pm 4^{\circ} \mathrm{C}$ ).

Another important stress factor is temperature. Elevated temperatures are applied to study the thermal stability of solar cells and to accelerate the degradation induced by other stressors ${ }^{42}$. Thermal degradation in the dark occurs in PSCs at elevated temperatures due to chemical and structural instabilities of the absorber materials $^{10,43}$ or transport layers ${ }^{44,45}$. Notably, some metal halide perovskites undergo phase transitions in the temperature range relevant to PV applications $s^{46,47}$. At the moment, the impact of phase transitions on the device lifetime is unclear and therefore so is the impact of different temperatures during (accelerated) ageing. As protocols should be applicable to any type of perovskites regardless of their phase transitions, ISOS protocols cannot accommodate all the possible temperature options. We are therefore suggesting maintaining the temperature settings described in the original ISOS protocols that would be above the tetragonal to cubic phase transition for $\mathrm{MAPbI}_{3}$. The effects of elevated temperatures on the device stability are assessed with the ISOS-D-2 test that is carried out at controlled elevated temperatures of 65 or $85^{\circ} \mathrm{C}$. While not explicitly controlled in ISOS-D-1 and D-2, we stress that monitoring and reporting the ambient relative humidity $(\mathrm{RH})$ is of critical importance because dry $(\mathrm{RH}<20 \%)$ and humid air represent dramatically different stress conditions for PSCs ${ }^{38,48}$. The ISOS-D-3 damp heat test specifically 


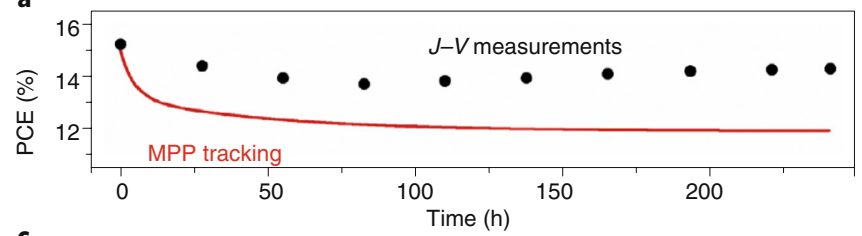

C

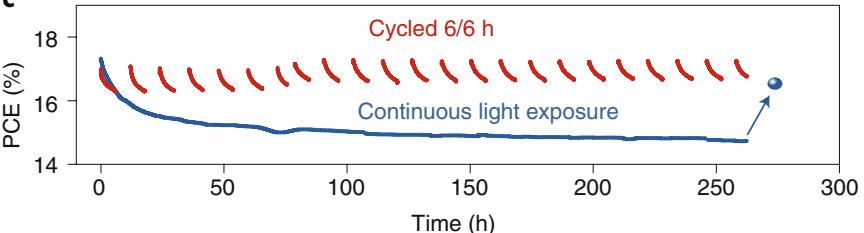

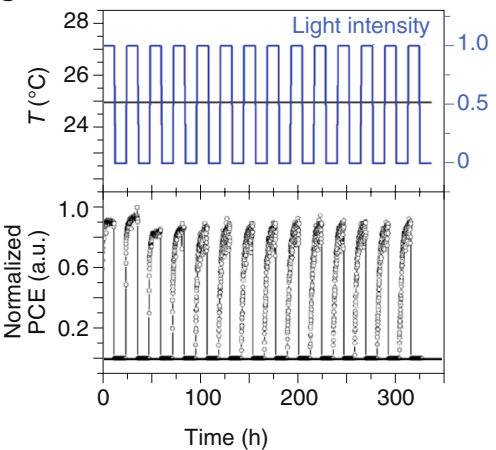

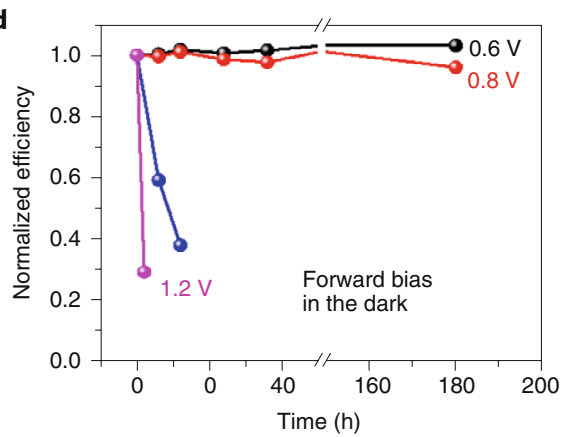

e

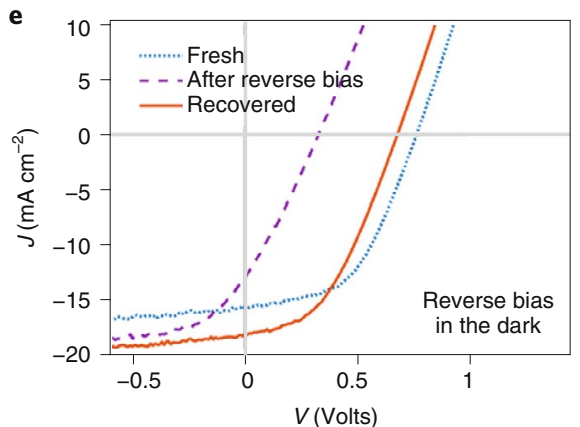

Fig. 1 | Specific features of PSC stability studies. a, PCE extracted from continuous MPP tracking (red curve) versus periodic $J-V$ scans collected from forward to reverse bias (black circles) for the same PSC. b, Normalized PCE of PSC subjected to repeated $12 \mathrm{~h}$ light on-off cycles at $25^{\circ} \mathrm{C}$ and $10 \% \mathrm{RH}$. c, PCE evolution of PSCs exposed to continuous (blue curve) or cycled (6/6 h, red curves) illumination by white-light-emitting diodes. d, Normalized PCE changes of PSCs exposed to different forward bias in the dark. e, Light $J-V$ curves for a fresh PSC, after $1 \mathrm{~min}$ at $-20 \mathrm{mAcm}{ }^{-2}$ and after recovering for over $3 \mathrm{~h}$ of MPP tracking. Panel $\mathbf{a}$ was adapted with permission from ref. ${ }^{8}$, Elsevier; panel $\mathbf{b}$ was adapted with permission from ref. ${ }^{82}$, Elsevier; panel $\mathbf{c}$ was adapted with permission from ref. ${ }^{4}$, Springer Nature Ltd; panel d was adapted with permission from ref. ${ }^{26}$, the American Chemical Society; panel e was adapted with permission ref. ${ }^{88}$, John Wiley and Sons.

takes into account the impact of humidity (set at $85 \% \mathrm{RH}$ ) when devices are kept at high elevated temperatures $\left(65\right.$ or $\left.85^{\circ} \mathrm{C}\right)$.

Light soaking tests (ISOS-L, 'Laboratory weathering' in the original ISOS protocols ${ }^{11}$ ) promote ion and defect migration in PSCs ${ }^{49-54}$ as well as phase segregation ${ }^{55,56}$ in the perovskite photoactive layer, which reduces efficiency. Additionally, light can catalyse or accelerate harmful chemical reactions, which lead to perovskite decomposition $^{57}$ or defect formation ${ }^{58}$. Detrimental changes in organic charge extraction layers, material intermixing at the interfaces ${ }^{59}$ and ion exchange between adjacent solar cell layers can also be caused by cell illumination ${ }^{52,60,61}$. As with $\mathrm{OPV}^{62}$ and $\mathrm{DSSC}^{63}$, the spectral composition of the light source also merits special attention, especially in the UV range. UV light assists perovskite decomposition ${ }^{64}$ and increases the non-radiative recombination rate in PSCs based on mesoporous $\mathrm{TiO}_{2}$ (ref. ${ }^{65}$,) which may thus require UV-blocking layers to become more stable. Recently, PSCs with novel transport layers have been shown to be tolerant to UV irradiation ${ }^{66,67}$. PSC stability may be affected differently by light in the UVA and UVB spectral ranges ${ }^{68}$.

In outdoor stability studies (ISOS-O), ageing occurs by illumination with natural sunlight in the ambient environment. Although these conditions are not necessarily reproducible (they depend on weather, location, season, and so on), the results of outdoor tests are the most relevant to device operation. Unlike other protocols, they can be directly applied to obtain realistic assessments of device lifetime, albeit specific to a given climate. Field tests can also determine whether the list of failure modes identified in the lab is complete and adequate for understanding reliability of the solar cell under real operation and, furthermore, can provide reference points for calculating acceleration factors that correlate lifetime under real-weather conditions to the lifetime obtained under the accelerated stress conditions. Previously, this approach was pursued to help establish IEC 61215 by correlating outdoor tests results for Si modules with results obtained from various acceleration tests ${ }^{69-71}$. To date, studies of PSC outdoor stability are scarce ${ }^{72-75}$, but the community has gained some critical insights with ISOS-O experiments, such as the importance of light-dark cycling ${ }^{74}$ and the unexpectedly high opencircuit voltage at low illumination intensities ${ }^{73}$.

Under the ISOS-O-1 protocol, periodic measurements of $J-V$ curves are done under illumination by a solar simulator. In ISOS-O-2, the $J-V$ measurements are periodically acquired under illumination by natural sunlight. ISOS-O-3 requires both in situ MPP tracking under natural sunlight and periodic performance measurements under a solar simulator. The results obtained by $J-V$ measurements and MPP tracking do not necessarily coincide in PSCs (Fig. 1a) ${ }^{8}$, although they generally have similar trends ${ }^{4,76}$. Therefore, it is crucial when characterizing PSCs to rigorously describe the load and recovery time before $J-V$ measurements. We encourage the use of MPP tracking, whenever possible, both as the most practical electrical-bias condition for ageing and as a reliable tool for PSC performance assessment (see further discussion below in 'Checklist for PSC stability studies'). However, we indicate MPP tracking as mandatory only at the third, most advanced level of ISOS protocols. For lower levels of sophistication, we give options of exposure under open-circuit condition or using a fixed voltage bias near the MPP (instead of active MPP tracking) in line with what was suggested in the original ISOS protocols ${ }^{11}$.

Thermal cycling in the dark (ISOS-T) and light-humiditythermal cycling ('solar thermal humidity cycling' in the original ISOS protocols ${ }^{11}$ ) (ISOS-LT) allow evaluation of the damage to PV 
Table 1 | Overview of existing ISOS protocols and suggested additional protocols that account for the properties of perovskite materials and devices

\begin{tabular}{|c|c|c|c|c|c|c|}
\hline Test ID & Light source & Temperature & Rel. humidity & Environment/Set-up & $\begin{array}{l}\text { Characterization } \\
\text { light source }\end{array}$ & Load \\
\hline \multicolumn{7}{|c|}{ Dark storage (ISOS-D) } \\
\hline ISOS-D-1 & None & $\begin{array}{l}\text { Ambient } \\
\left(23 \pm 4^{\circ} \mathrm{C}\right)\end{array}$ & Ambient & Ambient air & $\begin{array}{l}\text { Solar simulator or } \\
\text { sunlight }\end{array}$ & OC \\
\hline ISOS-D-2 & None & $65,85^{\circ} \mathrm{C}$ & Ambient & Oven, ambient air & Solar simulator & OC \\
\hline ISOS-D-3 & None & $65,85^{\circ} \mathrm{C}$ & $85 \%$ & Env. chamber & Solar simulator & OC \\
\hline ISOS-V-2 & None & $65,85^{\circ} \mathrm{C}$ & Ambient & Oven, ambient air & Solar simulator & \multirow{2}{*}{$\begin{array}{l}\text { Positive: } \\
V_{\mathrm{MPp}} ; V_{\text {oc }} \\
E_{g} / q ; J_{\mathrm{SC}} \\
\text { Negative: } \\
-V_{\text {oc }} J_{\mathrm{MPP}}{ }^{a}\end{array}$} \\
\hline ISOS-V-3 & None & $65,85^{\circ} \mathrm{C}$ & $85 \%$ & Env. chamber & Solar simulator & \\
\hline \multicolumn{7}{|c|}{ Light-soaking (ISOS-L) } \\
\hline ISOS-L-3 & Solar simulator & $65,85^{\circ} \mathrm{C}$ & $\sim 50 \%$ & Light, temperature \& RH & Solar simulator & MPP \\
\hline \multicolumn{7}{|c|}{ Outdoor stability (ISOS-O) } \\
\hline ISOS-O-1 & Sunlight & Ambient & Ambient & Outdoor & Solar simulator & MPP or OC \\
\hline ISOS-O-2 & Sunlight & Ambient & Ambient & Outdoor & Sunlight & MPP or OC \\
\hline ISOS-O-3 & Sunlight & Ambient & Ambient & Outdoor & $\begin{array}{l}\text { Sunlight and Solar } \\
\text { simulator }\end{array}$ & MPP \\
\hline \multicolumn{7}{|c|}{ Thermal cycling (ISOS-T) } \\
\hline ISOS-T-1 & None & RT to $65,85^{\circ} \mathrm{C}$ & Ambient & Hot plate/ oven & Solar simulator & OC \\
\hline ISOS-T-2 & None & RT to $65,85^{\circ} \mathrm{C}$ & Ambient & Oven/env. chamber & Solar simulator & OC \\
\hline ISOS-T-3 & None & -40 to $+85^{\circ} \mathrm{C}$ & $<55 \%{ }^{\mathrm{b})}$ & Env. chamber & Solar simulator & OC \\
\hline ISOS-LT-1 & Solar simulator & $\begin{array}{l}\text { Linear or step } \\
\text { ramping between } \\
\text { room temp. and } \\
65^{\circ} \mathrm{C}\end{array}$ & Monitored, uncontrolled & Weathering chamber & Solar simulator & MPP or OC \\
\hline ISOS-LT-2 & Solar simulator & $\begin{array}{l}\text { Linear ramping } \\
\text { between } 5^{\circ} \mathrm{C} \text { and } \\
65^{\circ} \mathrm{C}\end{array}$ & $\begin{array}{l}\text { Monitored, controlled at } 50 \% \\
\text { beyond } 40^{\circ} \mathrm{C}\end{array}$ & $\begin{array}{l}\text { Env. chamber with sun } \\
\text { simulator }\end{array}$ & Solar simulator & MPP or OC \\
\hline ISOS-LT-3 & Solar simulator & $\begin{array}{l}\text { Linear ramping } \\
\text { between }-25^{\circ} \mathrm{C} \\
\text { and } 65^{\circ} \mathrm{C}\end{array}$ & $\begin{array}{l}\text { Monitored, controlled at } 50 \% \\
\text { beyond } 40^{\circ} \mathrm{C}\end{array}$ & $\begin{array}{l}\text { Env. chamber with sun } \\
\text { simulator and freezing }\end{array}$ & Solar simulator & MPP or OC \\
\hline
\end{tabular}

Each test group is divided into three levels of sophistication that reflect the complexity of required equipment and the harshness of the applied stress. Reported ISOS protocols are taken from ref. ${ }^{11}$ Proposed additional ISOS protocols are printed in bold. ${ }^{\mathrm{a}} V_{\mathrm{OC}}, V_{\text {MPP, }}$ and $J_{\mathrm{MPp}}$ are determined from light $J-V$ curves measured under standard solar cell testing conditions on a fresh device. $E_{\mathrm{g}}$ and $q$ are the band

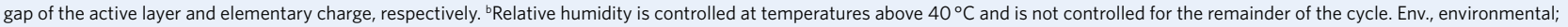

$\mathrm{OC}$, open-circuit condition; MPP, maximum power point; $\mathrm{RT}$, room temperature; $\mathrm{RH}$, relative humidity.

devices caused by diurnal and seasonal variations in the weather in terms of solar radiation, temperature and humidity. These tests are relevant for any outdoor-dedicated PV technology (including PSCs) because they simulate realistic conditions, stimulate failure mechanisms related to delamination of layers or contacts ${ }^{77}$ and are included in the qualification standards ${ }^{78}$. Particularly for PSCs, degradation under varying temperature could be more severe than that under constant extreme temperatures, which is attributed to the effect of ion accumulation at the contacts ${ }^{20}$. Delamination from thermal cycling was mitigated by adding a flexible polymer buffer layer around the mechanically fragile perovskite, which resulted in PSCs retaining more than $90 \%$ of their performance after 200 cycles between -40 and $85^{\circ} \mathrm{C}^{77}$. Temperature and illumination cycling, which resembles weather conditions in central Europe 
for several representative days, was applied to PSCs under a nitrogen atmosphere ${ }^{79}$. This study enabled from a temperature point of view insight into the real-world operation of PSCs and emphasized the complex interplay of temperature-dependent transient effects during the day with reversible and irreversible degradation processes. Depending on the available equipment, temperature cycling varies from simple turning on and off a hotplate installed in an ambient environment to complex temperature and humidity cycles in an environmental chamber. Examples of such cycles are available elsewhere ${ }^{11,78}$.

\section{Suggested specific ISOS protocols relevant for PSCs}

Recently some ageing protocols for PSC were suggested ${ }^{10,28}$; they mostly feature subsets of the original ISOS protocols described above, although some additional ideas, particularly concerning the application of electrical-bias ${ }^{10}$, were also introduced. Below we suggest extensions of the ageing procedures, summarized in Table 1, to account for the specific properties of perovskite materials and solar cells (proposed additional ISOS protocols in Table 1 are in bold). Although a major part of the original motivation for the ISOS protocols was to limit conditions for each level to facilitate comparison, data are limited on the protocols discussed below. We therefore propose a reporting framework, give some example conditions, and discuss why these might be relevant. As in the case of the existing ISOS protocols, we recommend testing the device following the basic procedure (level 1) as a minimum requirement. A similar framework is likely to be useful for OPV and other emerging PV technologies. If these protocols become widespread over the next few years, the community can adopt a more informed decision on a limited number of consensus conditions.

\section{Light-dark cycling (ISOS-LC)}

Various PSC degradation modes have repeatedly been shown to be entirely or partly reversible in the dark (often referred to as metastability) ${ }^{20,36,51,58,74,80-83}$. Therefore, cycling through light-dark periods to simulate day-night cycles constitutes a significantly different stress test than applying constant illumination (ISOS-L) ${ }^{4,74}$. Two opposite types of dynamics are reported in the literature: reversible photoinduced PCE increase with subsequent decrease in the $\operatorname{dark}^{74,82}$ (Fig. 1b) and photo-induced degradation with recovery in the dark $^{51,58}$ (Fig. 1c). Reversible performance loss is attributed to cation redistribution ${ }^{51}$, metastable defect formation ${ }^{58}$ and reversible chemical reactions ${ }^{57}$. The PCE improvement under illumination after storage in the dark is commonly attributed to the neutralization of interfacial defects by photogenerated charge carriers or to changes in the built-in electric field due to ion migration ${ }^{84-86}$. The PCE dynamics during a cycle depends on the status of cell degradation $^{81}$. For example, PSCs have shown a 'fatigue' effect: while the PCE decreased in the dark and recovered under illumination, the rate of PCE restoration reduced with each consecutive light-dark cycle (Fig. 1b) ${ }^{82}$. Such metastability is attributed to the migration of ions, which is known to be pronounced in metal halide perovskites ${ }^{83}$. Reversible and irreversible degradation mechanisms may co-exist in a given $\mathrm{PSC}^{79,81,87}$.

The ISOS protocols revised for PSCs should, therefore, include a group of light-dark cycling protocols to account for the recovery phenomena (ISOS-LC in Table 1). For the ISOS-LC experiments, we suggest exposing the cells to simulated sunlight turned on and off with cycle periods of 2,8 , or $24 \mathrm{~h}$ and duty cycles (light:dark) of $1: 1$ or $1: 2$. Of the suggested conditions, $24-\mathrm{h}-$ long cycles $(12 \mathrm{~h}$ light and $12 \mathrm{~h}$ dark or $8 \mathrm{~h}$ light and $16 \mathrm{~h}$ dark) mimic the diurnal sun cycle. However, because the interplay between degradation and recovery in realistic conditions can be complex ${ }^{79}$ and depend on cell history, varying cycle duration and duty cycle should provide additional information on the extent of reversibility and sufficient recovery times. At the ISOS-LC-1 level, the solar cell is
Table 2 | Overview of suggested ISOS-I protocols for ageing experiments in an inert atmosphere

\begin{tabular}{llll} 
Test ID & Elevated temperature & Electrical bias & Light \\
\hline ISOS-D-1| & - & - & - \\
ISOS-D-2I & $\checkmark$ & - & - \\
ISOS-V-1| & - & $\checkmark$ & - \\
ISOS-V-2| & $\checkmark$ & $\checkmark$ & - \\
ISOS-L-1| & - & - & $\checkmark$ \\
ISOS-L-2I & $\checkmark$ & - & $\checkmark$ \\
ISOS-T-1| & Cycled & - & - \\
ISOS-T-2I & Cycled & - & - \\
ISOS-T-3I & Cycled & - & - \\
ISOS-LC-1| & - & - & Cycled \\
ISOS-LC-2I & $\checkmark$ & - & Cycled \\
ISOS-LC-3I & $\checkmark$ & - & Cycled \\
\hline
\end{tabular}

Ticks and dashes denote the presence and absence of the stress, respectively. In case of temperature, '-' refers to room temperature.

maintained at ambient conditions while the temperature and $\mathrm{RH}$ are monitored, but not controlled. At the ISOS-LC-2 level, the cell is maintained at a fixed set point temperature of 65 or $85^{\circ} \mathrm{C}$ in the ambient atmosphere. At the ISOS-LC-3 level, $\mathrm{RH}$ is held at $50 \%$ and high temperatures.

\section{Electrical bias in the dark (ISOS-V)}

Electrical bias causes PSC degradation ${ }^{25,26,88,89}$ by triggering ion migration $^{26}$ or charge carrier accumulation that result in thermally activated traps formation ${ }^{90}$ or detrimental electrochemical reactions ${ }^{23}$. Electric fields also promote moisture-initiated perovskite degradation ${ }^{89,91}$ because moisture ingress can lead to the formation of hydrated perovskite phases containing mobile ions, whose drift accelerates the degradation ${ }^{92}$. Both positive (Fig. 1d) and negative (Fig. 1e) biases are potentially harmful ${ }^{26,88}$ and might occur during the operation of solar panels. In our view, ISOS protocols revisited for PSCs should include the ISOS-V group of testing in which the behaviour of the cell is analysed when exposed to a certain electrical bias in the dark (Table 1).

Usually, a solar cell is kept near its MPP (that is, positively biased with voltage $V<V_{\mathrm{OC}}$ ); however, disconnected cells under illumination are biased at open-circuit voltages (typically, $\sim 1 \mathrm{~V}$ for iodine single-junction PSCs). Therefore, we suggest applying a voltage equal to $V_{\mathrm{MPP}}$ or $V_{\mathrm{OC}}$ (as measured under AM1.5G one sun illumination on a fresh device) as a positive bias condition. Since bias-induced degradation effects may have a threshold behavior ${ }^{26}$, we recommend voltages below the bandgap energy divided by the charge of the electron to avoid unnatural overstressing. In Si PVs, constant-current stress was shown to mimic MPP operation under full sunlight exposure, while testing current-induced degradation is technically easier ${ }^{93}$. To date, however, no similar data exist for PSCs, so such stability tests might also be useful.

For a partly shaded solar module (shaded by clouds, dirt, nearby trees, and so on), shaded solar cells can be forced to operate under reverse bias to match the current flow through the rest of the module ${ }^{88,94,95}$. The choice of negative-bias stressing conditions depends on the anticipated module connection scheme, particularly on the use and choice of bypass diodes. At present, experience with perovskite modules is insufficient, so it is reasonable to learn from both experiments: with a constant negative bias applied (for example, $-V_{\mathrm{OC}}$ ), which is relevant for modules with bypass diodes, and with the current enforced up to $-J_{\mathrm{MPP}}$ (which in the dark would 


\section{Table 3 | Suggested checklist for reporting data from stability tests}

\begin{tabular}{|c|c|}
\hline Key aspects & Characteristics \\
\hline \multirow[t]{3}{*}{$\begin{array}{l}\text { Initial solar cell } \\
\text { characterization }\end{array}$} & $\begin{array}{l}\text { Current-voltage } \\
(J-V) \text { curves }\end{array}$ \\
\hline & $\begin{array}{l}\text { MPP tracking or } \\
\text { photocurrent at MPP }\end{array}$ \\
\hline & EQE/IPCE spectra \\
\hline \multirow[t]{4}{*}{ Encapsulation } & Wiring \\
\hline & $\begin{array}{l}\text { Front- and back- } \\
\text { side encapsulation } \\
\text { layer(s) }\end{array}$ \\
\hline & Edge sealant \\
\hline & Geometry \\
\hline \multirow[t]{6}{*}{ Ageing conditions } & Light \\
\hline & Temperature \\
\hline & Atmosphere \\
\hline & $\begin{array}{l}\text { Electrical bias } \\
\text { condition }\end{array}$ \\
\hline & $\begin{array}{l}\text { Cycling procedure } \\
\text { (if applicable) }\end{array}$ \\
\hline & $\begin{array}{l}\text { Comply with known } \\
\text { protocols (IEC, ISOS } \\
\text { and so on)? }\end{array}$ \\
\hline
\end{tabular}

Ageing time

Measurements during ageing

\section{Details to be reported}

Light source (light source type, intensity, spectrum, filters applied, calibration), scan speed, direction, dwelling time, the number of power line cycles (NPLC), preconditioning, and so on

Hardware, tracking algorithm, delay time, tracking duration

Indicating the lock-in frequency and light bias if used, and if monochromatic light is smaller than active area, or larger and an optical mask applied. Calculated $J_{\mathrm{SC}}$ and its comparison to $J_{\mathrm{SC}}$ obtained from the $J-V$ data

Materials, processing conditions, addition of a protective sealant

Materials (reference or composition, thickness), processing conditions (environment, temperature, duration)

Materials (reference, thickness, width), processing conditions (environment, curing and so on)

Rim (minimum distance between encapsulation edge and active area edge), device active area; picture or a scheme of the device

Light source type, intensity, spectrum, filters applied, calibration

In shadow and/or under illumination, temperature sensor type

Air/glovebox/sealed pouch/environmental chamber, and so on; RH (controlled or monitored)

Open circuit/maximum power point/short circuit/constant load

Dwell and period times

Stress duration and corresponding performance loss, resting times (for example, without stress).

Periodically recorded Recording frequency, scan parameters (similar to 'Initial solar cell characterization')

$J-V$ curves

Recovery before

measurements

MPP tracking

Recovery time and conditions prior to the measurements.

Tracking parameters (similar to 'Initial solar cell characterization')

Other periodic

measurements

(if applied)

Number of samples

Outdoor stability

Location and time of exposure

Weather conditions throughout the

exposure period
Number of solar cells of each type tested under each ageing condition, statistical analysis (if applicable). Number of samples still operating above a specified efficiency level at the end of the ageing test.

Place or coordinates; dates and total amount of hours of exposure.

Temperature, humidity, sunlight irradiance (preferably in tabulated format), wind speed, and so on. mean a relatively high negative bias applied to the cell). The latter condition simulates the situation of a partially shaded module in the absence of a bypass diode. Practical negative-bias conditions depend on the details of the module layout. The three sophistication levels of the ISOS-V protocols differ by the level of control over the sample temperature and atmosphere and the required equipment, which is similar to the corresponding ISOS-D protocols (Table 1$)^{11}$.

Electrical bias can redistribute charged species across the PSC, which might be reversible after stress removal ${ }^{26}$. Thus, we recommended tracing the solar cell recovery after ageing by storing it in the dark under open-circuit (disconnected) conditions and periodically checking its performance until it reaches saturation. For a similar reason, measuring the steady state of the $J-V$ curve may be difficult after electrical biasing. We recommend using MPP tracking (or a stabilized current at a constant voltage close to MPP for ISOS-V-1 and ISOS-V-2) to account for possible transient effects.
It may also be informative to report the evolution of the in situ dark current (or voltage in constant current density mode) during stressing in addition to periodic $J-V$ measurements in ISOS- $V$ protocols.

\section{Intrinsic stability testing (ISOS-I)}

The stress factors can be divided into two groups: intrinsic and extrinsic. The intrinsic factors include light, temperature, and electrical bias (relevant regardless of the cell encapsulation or protective environment), and the extrinsic factors are governed by the cell interactions with ambient species such as oxygen and/or moisture (which are relevant assuming imperfect device encapsulation).

Generally, 'encapsulation' of devices refers to the protection of the solar cells by gas-barrier materials, which delays the contact between the cell and ambient air (especially moisture). Encapsulation can be done by glass-glass sealing, lamination of rigid or flexible gas-barrier materials, direct deposition of protective layers 
Table 4 | Conditions of stability analysis of selected PSCs analyzed under continuous illumination for over $1000 \mathrm{~h}$. Only cells losing less than $15 \%$ of initial PCE are included

\begin{tabular}{|c|c|c|c|c|c|c|c|c|c|c|}
\hline $\begin{array}{l}\text { Light } \\
\text { source }\end{array}$ & UV filter & Reported & $\begin{array}{l}\text { Intensity } \\
\text { (Suns) }\end{array}$ & $\mathrm{T}\left({ }^{\circ} \mathrm{C}\right)$ & Atmosphere & $\begin{array}{l}\text { Encap- } \\
\text { sulation }\end{array}$ & Cell structure & $\begin{array}{l}\text { Initial } \\
\text { PCE (\%) }\end{array}$ & $\begin{array}{l}\text { Time } \\
\text { (h) }\end{array}$ & Ref. \\
\hline \multirow[t]{2}{*}{$\begin{array}{l}\text { Sulfur } \\
\text { plasma }\end{array}$} & - & $\begin{array}{l}\text { 'Triple A class' sulfur } \\
\text { plasma lamp, Plasma-I } \\
\text { AS } 1300 \text { Light Engine } \\
\text { (http://www.plasma-i. } \\
\text { com/plasma-i- } \\
\text { products.htm). }\end{array}$ & 0.77 & $30^{\circ} \mathrm{C}$ & $\begin{array}{l}\text { Ambient Air } \\
10 \%-20 \% \mathrm{RH}\end{array}$ & No & $\begin{array}{l}\mathrm{ITO} / \mathrm{SnO}_{2}\left(\mathrm{FA}_{0.76} \mathrm{MA}_{0.15}\right. \\
\left.\mathrm{CS}_{0.09}\right)_{0.97} \mathrm{~Pb}\left(\mathrm{I}_{0.89} \mathrm{Br}_{0.11}\right)_{2.97} \\
\mathrm{EH} 44 / \mathrm{MoOx} / \mathrm{Al}\end{array}$ & 16.6 & 1500 & 49 \\
\hline & - & $\begin{array}{l}\text { Sulfur plasma lamp } \\
\text { from LG ( } 6000 \mathrm{~K} \\
\text { blackbody). }\end{array}$ & 1 & $35^{\circ} \mathrm{C}$ & $\begin{array}{l}\text { Ambient Air } \\
40 \% \mathrm{RH}\end{array}$ & No & 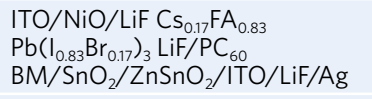 & 14.5 & 1000 & 148 \\
\hline \multirow[t]{6}{*}{ White LED } & - & White LED illumination & 1 & RT & $\begin{array}{l}\mathrm{N}_{2} \text { filled } \\
\text { chamber }\end{array}$ & No & $\begin{array}{l}\text { ITO/SnO } \mathrm{S}_{2} / \mathrm{PCBM}: \mathrm{PMMA} / \\
\mathrm{Rb}_{0.05} \mathrm{Cs}_{0.1} \mathrm{FAPbl} \mathrm{PMMM}_{3} \mathrm{PM} / \\
\text { Spiro-OMeTAD/Au }\end{array}$ & 20.4 & 1000 & 149 \\
\hline & - & White light LED array & 1 & $\begin{array}{l}55^{-} \\
60^{\circ} \mathrm{C}\end{array}$ & $\begin{array}{l}\text { Ar filled } \\
\text { chamber }\end{array}$ & No & 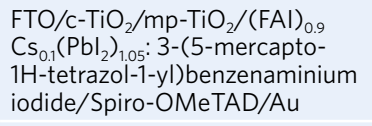 & 20.9 & 1000 & 150 \\
\hline & - & $\begin{array}{l}\text { White LED (XLamp } \\
\text { CXA2011 1300 K CCT) }\end{array}$ & 1 & RT & $\begin{array}{l}\mathrm{N}_{2} \text { filled } \\
\text { chamber }\end{array}$ & No & $\begin{array}{l}\text { ITO/C } \mathrm{C}_{60}-\mathrm{SAM} \text { FA } \mathrm{A}_{0.83} \mathrm{MA}_{0.17} \\
\mathrm{~Pb}_{1.1} \mathrm{Br}_{0.5} \mathrm{I}_{2.8} \mathrm{PDCBT} / \mathrm{Ta}-\mathrm{WO}_{x} / \mathrm{Au}\end{array}$ & 21.2 & 1050 & 151 \\
\hline & - & $\begin{array}{l}\text { Array of white LEDs } \\
\text { was powered by a } \\
\text { constant current }\end{array}$ & 1 & $60^{\circ} \mathrm{C}$ & $\begin{array}{l}\mathrm{N}_{2} \text { filled } \\
\text { chamber }\end{array}$ & No & $\begin{array}{l}\mathrm{FTO} / \mathrm{c}-\mathrm{TiO}_{2} / \mathrm{mp}-\mathrm{TiO}_{2} \\
\mathrm{CsFAMAPbl} \\
\mathrm{Br}_{x} \mathrm{CuSCN} / \mathrm{r}-\mathrm{GO} / \mathrm{Au}\end{array}$ & 20.4 & 1000 & 131 \\
\hline & - & White LED lamp & 1 & $55^{\circ} \mathrm{C}$ & $\begin{array}{l}\mathrm{N}_{2} \text { filled } \\
\text { chamber }\end{array}$ & No & 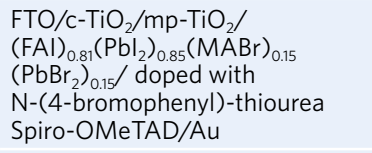 & 21.5 & 1500 & 152 \\
\hline & - & White LED lamp & 1 & RT & $\begin{array}{l}\mathrm{N}_{2} \text { filled } \\
\text { chamber }\end{array}$ & No & $\begin{array}{l}\mathrm{FTO} / \mathrm{c}-\mathrm{TiO}_{2} / \mathrm{mp}-\mathrm{TiO}_{2} / \\
\mathrm{MAPbl}_{3} / \mathrm{PTAA} / \mathrm{Au}\end{array}$ & 16.4 & 1000 & 21 \\
\hline \multirow{4}{*}{$\begin{array}{l}\text { Metal } \\
\text { halide or } \\
\text { xenon- } \\
\text { plasma } \\
\text { lamp }\end{array}$} & No & $\begin{array}{l}\text { Light-soaking chamber, } \\
\text { K3600-MH300, } \\
\text { McScience Inc. }\end{array}$ & 1 & RT & $\begin{array}{l}\mathrm{N}_{2} \text { filled } \\
\text { chamber }\end{array}$ & Yes & $\begin{array}{l}\mathrm{FTO} / \mathrm{La}-\mathrm{BaSnO}_{3} / \mathrm{MAPbl}_{3} / \\
\mathrm{NiO} / \mathrm{FTO} / \text { glass }\end{array}$ & 21.2 & 1000 & 66 \\
\hline & Yes & $\begin{array}{l}\text { Class AAA solar sim. } \\
\text { from Newport equip. } \\
\text { with a } 1000 \text { W Xenon } \\
\text { lamp. } \\
\text { AAA class simulator } \\
\text { using a plasma lamp } \\
\text { with a spectrum that } \\
\text { exactly superimposes } \\
\text { to the standard. }\end{array}$ & 1 & $55^{\circ} \mathrm{C}$ & $\begin{array}{l}\text { Ar filled } \\
\text { chamber or } \\
\text { encapsulated }\end{array}$ & Yes & $\begin{array}{l}\mathrm{FTO} / \mathrm{c}-\mathrm{TiO}_{2} / \mathrm{mp}-\mathrm{TiO}_{2} / \\
\mathrm{ZrO}_{2}(5-\mathrm{AVA})_{x}(\mathrm{MA})_{1-\mathrm{x}} \\
\mathrm{Pbl}_{3} / \text { Carbon }\end{array}$ & 11.9 & 10,000 & 133 \\
\hline & No & $\begin{array}{l}\text { Newport solar } \\
\text { simulator (model } \\
\text { 91192) giving light } \\
\text { with AM } 1.5 \text { G spectral } \\
\text { distribution }\end{array}$ & 1 & & $\begin{array}{l}\text { Ambient air, } \\
\text { unspecified }\end{array}$ & No & $\begin{array}{l}\mathrm{FTO} / \mathrm{c}-\mathrm{TiO}_{2} / \mathrm{mp}-\mathrm{TiO}_{2} / \mathrm{ZrO}_{2} \\
(5-\mathrm{AVA})_{x}(\mathrm{MA})_{1-x} \mathrm{Pbl}_{3} / \text { Carbon }\end{array}$ & 10 & 1008 & 153 \\
\hline & No & $\begin{array}{l}\text { Atlas SUNTEST } \\
\text { XLS + (1,700 W air- } \\
\text { cooled xenon lamp) } \\
\text { light-soaking chamber } \\
\text { under simulated } \\
\text { full-spectrum AM1.5 } \\
\text { sunlight. }\end{array}$ & 0.76 & $\begin{array}{l}70- \\
75^{\circ} \mathrm{C}\end{array}$ & $\begin{array}{l}\text { Ambient air } \\
40 \%-50 \% \mathrm{RH}\end{array}$ & Yes & $\begin{array}{l}\mathrm{FTO} / \mathrm{NiO} /\left(\mathrm{FA}_{0.83} \mathrm{MA}_{0.17}\right)_{0.95} \mathrm{Cs}_{0.05} \\
\mathrm{~Pb}\left(\mathrm{I}_{0.9} \mathrm{Br}_{0.1}\right)_{3}+\mathrm{BMIMBF}_{4} / \\
\mathrm{PCBM} / \mathrm{Cr}\left(\mathrm{Cr}_{2} \mathrm{O}_{3}\right) / \mathrm{Au}\end{array}$ & $\sim 19$ & 1885 & 154 \\
\hline \multirow[t]{4}{*}{$\begin{array}{l}\text { Solar } \\
\text { simulator } \\
\text { with } \\
\text { unspecified } \\
\text { light source }\end{array}$} & Yes & $\begin{array}{l}\text { 'Solar cell light } \\
\text { resistance test system } \\
\text { (Model BIR- 50, } \\
\text { Bunkoh-Keiki Co., LTD) } \\
\text { equipped with a Class } \\
\text { AAA solar simulator' }\end{array}$ & 1 & $\begin{array}{l}45^{-} \\
50^{\circ} \mathrm{C}\end{array}$ & & Yes & $\begin{array}{l}\mathrm{FTO} / \mathrm{NiMg}(\mathrm{Li}) \mathrm{O} / \mathrm{MAPbl}_{3} / \\
\mathrm{PCBM} / \mathrm{Ti}(\mathrm{Nb}) \mathrm{O} / \mathrm{Ag}\end{array}$ & 18.3 & 1000 & 155 \\
\hline & Yes & $\begin{array}{l}\text { 'Sun Simulator } \\
\text { Sumitomo Heavy } \\
\text { Industries Advanced } \\
\text { Machinery' }\end{array}$ & 1 & $35^{\circ} \mathrm{C}$ & $\mathrm{N}_{2}$ & Yes & $\begin{array}{l}\text { ITO/BDPSO/MAPbl } / \\
\mathrm{C}_{60} / \mathrm{BCP} / \mathrm{Ag}\end{array}$ & 17.2 & 1300 & 156 \\
\hline & $\begin{array}{l}\text { Not } \\
\text { specified }\end{array}$ & $\begin{array}{l}\text { 'AM.1.5 G solar } \\
\text { simulator' }\end{array}$ & 1 & & & Yes & $\begin{array}{l}\mathrm{FTO} / \mathrm{PEDOT}: \mathrm{PSS} /(\mathrm{BA})_{2}(\mathrm{MA})_{3} \\
\mathrm{~Pb}_{4} \mathrm{I}_{13} / \mathrm{PCBM} / \mathrm{Al}\end{array}$ & 12.5 & 2250 & 157 \\
\hline & No & 'AM 1.5 G illumination' & & & Air 38\% RH & & $\begin{array}{l}\mathrm{PET} / \mathrm{Gr} / \mathrm{TiO}_{2} / \mathrm{PCBM} \mathrm{MAPbl}_{3} / \\
\text { Spiro-OMeTAD:cross-stacking } \\
\text { carbon nanotube/All Carbon } \\
\text { Electrode }\end{array}$ & 11.9 & 1014 & 158 \\
\hline Outdoor & No & & Variable & $\begin{array}{l}\text { Variable } \\
\text { up to } \\
45^{\circ} \mathrm{C}\end{array}$ & & Yes & $\begin{array}{l}\mathrm{FTO} / \mathrm{c}-\mathrm{TiO}_{2} / \mathrm{mp}-\mathrm{TiO}_{2} / \mathrm{ZrO}_{2} / \\
(5-\mathrm{AVA})_{x}(\mathrm{MA})_{1-\mathrm{x}} \mathrm{Pbl}_{3} / \mathrm{mcarbon}\end{array}$ & 12.9 & 1056 & 72 \\
\hline
\end{tabular}

$\mathrm{RT}$, room temperature; $\mathrm{RH}$, relative humidity 


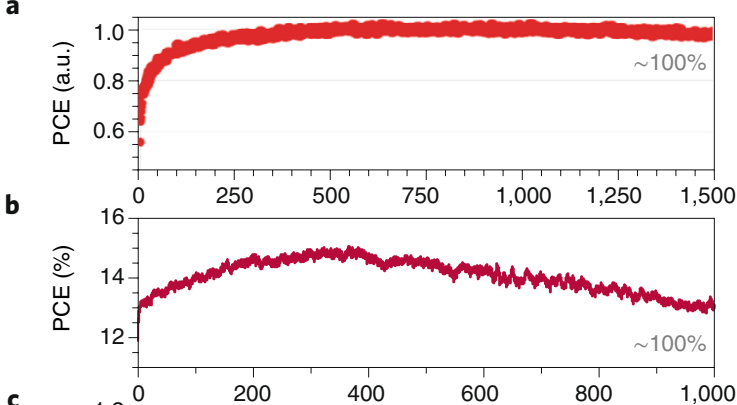

C

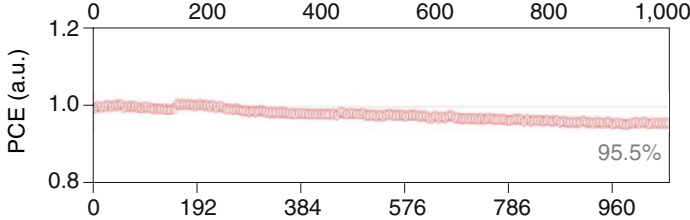

d

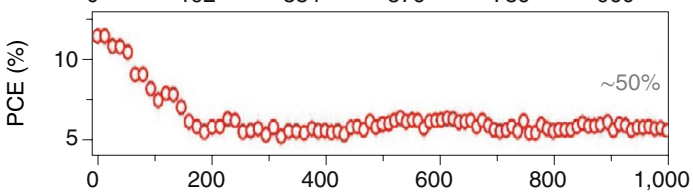

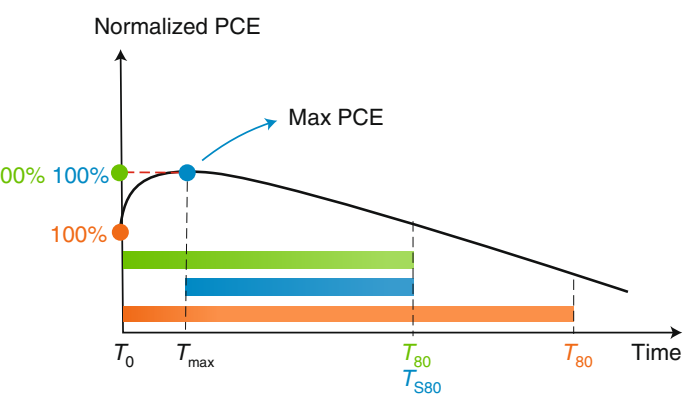

Fig. 2 | Different degradation dynamics in perovskite solar cells and common practices for estimating $T_{80}$. a-d, Examples of some of the most stable PSCs reported so far, demonstrating a variety of possible PCE time profiles upon ageing under 1 sun illumination. e,f, Common practices in the $T_{80}$ estimations. The black curves show schematically how PCE evolves with ageing time in the case of 'burn-in' effect (e) and in the case of nonmonotonic PCE (f). The three strategies depicted to estimate $T_{80}$ differ in how the initial PCEs ('100\%') are estimated and the choice of starting point of the ageing timer (shown in the figure as circles of corresponding colours). In the first strategy, $80 \%$ PCE is counted from the initial PCE at $t=T_{0}$ (shown in orange). In the second strategy, $80 \%$ PCE is counted from the back-extrapolated 'after burn-in' PCE in panel $\mathbf{e}$ (red dashed line indicates the extrapolation) or from the PCE maximum in panel $\mathbf{f}$ (red dashed line used to guide the eyes); in both cases the timer starts at $t=T_{0}$ (shown in green). In the final strategy, $80 \%$ PCE is counted from the PCE at $t=T_{\text {max }}$ in panel $\mathbf{f}$ or at $t=T_{\text {burn-in }}$ in panel $\mathbf{e}$, and the ageing timer starts at corresponding timestamps (shown in blue). Panel $\mathbf{a}$ is adapted with permission from ref. ${ }^{49}$, Elsevier; panel $\mathbf{b}$ is adapted with permission from ref. ${ }^{148}$, Elsevier; panel $\mathbf{c}$ is adapted with permission from ref. ${ }^{72}$, Springer Nature Ltd; panel $\mathbf{d}$ is adapted with permission from ref. ${ }^{65}$, IEEE.

or a combination of these processes. Extrinsic stability depends on the device sensitivity to air and on the properties of the barrier material (including their chemical compatibility with the device). A full understanding of degradation of encapsulated devices requires knowledge of the stability and properties of the gas barrier. Specific tools exist to characterize the gas-barrier properties and to determine the amount of moisture that has permeated orthogonally ${ }^{96-99}$ and laterally ${ }^{100,101}$ within the encapsulation. Any measurement of the lateral permeation from the encapsulation edge should mimic, to the extent possible, the operational encapsulation and take into account the interfacial permeation that is not considered in gas-barrier measurements of bulk materials. Control of the self-resistance of encapsulation is particularly important because ageing tests, which involve high temperature, high humidity and UV irradiation, could degrade the gas-barrier protection, leading to a dramatic drop in PV performance. Therefore, we recommend ageing encapsulating materials under the same ageing conditions as done with encapsulated devices and to determine the gas-barrier properties after ageing. Developing dedicated encapsulation procedures constitutes a separate technological challenge, especially for PSCs ${ }^{77,102-105}$.

In the vast majority of studies, the barrier properties of the encapsulants are unknown, which inhibits the ability to differentiate between intrinsic and extrinsic cell stability. Even if the device is nominally 'unencapsulated', the top evaporated electrode can play the role of barrier (with unknown properties). This has motivated numerous studies to focus on intrinsic PSC stability by stressing the cells in an inert atmosphere, for example, in sealed pouches, or with equipment installed in inert atmosphere glove boxes or environmental chambers. This approach provided important insights into PSC degradation mechanisms and is helpful for differentiating between how thermal stress, light, electrical bias and the cycles thereof affect device degradation ${ }^{4,106,107}$.

We suggest including protocols to address the intrinsic stability of solar cells in inert atmospheres (nitrogen, argon, and so on). The protocol is labelled by the index 'I' at the end of the protocol name (Table 2) to indicate an inert atmosphere in the corresponding test, with the other parameters kept the same. For example, ISOS-L-1I stands for the intrinsic photo-stability at room temperature (similar to ISOS-L-1 except that the atmosphere is inert), ISOS-L-2I stands for the intrinsic photo-stability at elevated temperature, and so on. The latter protocol is essential because it is often used to determine the lifetime of a given PSC in research papers. Notably, the new family of protocols includes ageing experiments with a single stress factor (only heat in ISOS-D-2I; only electrical bias in ISOS-V-1I; only light in ISOS-L-1I, and so on), which simplifies the analysis of degradation modes. We also included ISOS-LC-3I and ISOS-T-3I protocols in Table 2 despite the original conditions requiring a certain relative humidity value. The advanced, level 3 protocols differ from LC-1,2 and T-1,2 in the temperature cycle and some technicalities that are reported elsewhere ${ }^{11}$. For instance, ISOS-T-3 goes to $-40^{\circ} \mathrm{C}$, while ISOS-T- 2 only down room temperature. We therefore suggest performing ISOS-LC-3I and ISOS-T-3I tests in the absence of humidity, given that I-tests are conducted in an inert atmosphere, to stress the device with a harsher temperature cycle.

Note that encapsulation not only inhibits reactions with ambient species but may also prevent out-diffusion of volatile perovskite decomposition products from the device. Recently the light-induced degradation of unencapsulated PSCs was also shown to accelerate 
Table 5 | Possible figures of merit for evaluating PSC stability

\begin{tabular}{lll} 
& FOM options & Stress Conditions \\
\hline 1 & $T_{80}$ & Continuous stress \\
2 & $T_{580}$ & \\
\hline
\end{tabular}

Description and applicability

$20 \%$ of PCE decay from initial PCE $(t=0)$.

$20 \%$ of PCE decay from a certain PCE value during the ageing experiment, corresponding to $t=T_{\max }$ or $t=T_{\text {burn-in }}$ : from the extrapolated $t=0$ value from the postburn-in decay fitting (see Fig. $2 e, f$ ). For cells with an increase in PCE, $T_{80}$ should be estimated for time at which the efficiency has dropped to $80 \%$ of the maximum PCE, with the complete time from $t=0$ to this point quoted as the $T_{80}$ value.

In case $T_{80}$ is not reached within the timeframe of the ageing experiment, so the decrease observed over first $1000 \mathrm{~h}$ should be reported in addition to (optionally) an extrapolation applied to determine $T_{80}$ and/or $T_{580}$.

$4 \quad T_{80}$ analogue, corrected for

If the restoration process has been tested after the stress removal. the recovery processes

$5 \quad T_{95}$ and $T_{595}$

Analogous to $T_{80}$ and $T_{580}$, apart from to $95 \%$ of the $t=0$, maximum, or post-burn-in back-extrapolated $t=0$ PCE.

$6 \quad T_{80}$ analogue for energy output Cycled stress

For cycled illumination conditions, especially in the case of non-monotonic PCE versus per cycle or average PCE value

during the cycle time curves

in an ultrahigh vacuum ${ }^{108}$. Therefore, encapsulated PSCs may have a longer lifetime than unencapsulated PSCs, even for degradation experiments conducted in an inert atmosphere. In addition, the environment in which the PSC is encapsulated may also play a role. Thus, reporting the presence or absence and the details of encapsulation is also mandatory in I protocols.

\section{Checklist for PSC stability studies}

To compare results and ensure reproducibility, sufficient information must be reported about ageing experiments, in addition to giving a detailed description of device preparation ${ }^{27}$. Table 3 proposes a checklist for reporting stability data in accordance with that introduced by Nature journals for reporting PV performance data $^{109}$. We stress that, even if a parameter is not controlled during the ageing experiment (for example, temperature or RH in 'ISOS-1' protocols), it is still important to monitor and report the parameters listed in Table 3.

In particular, we recommend specifying the number of samples studied in each ageing test. According to a critical analysis of the quality of PSC stability studies ${ }^{27}$, nearly half of the studies consider only a single sample of each kind, which is particularly worrisome for PSCs that are typically characterized by relatively low reproducibility. Ideally, statistics should be provided to account for sampleto-sample and batch-to-batch variations. The same work provides estimates of the desired sample size ${ }^{27}$.

Stability data are often reported in the form of normalized parameters as a function of ageing time, while only specifying the performance of a fresh representative device (the 'champion' or average). Thus, the reported stabilities and efficiencies may be measured on different devices and thus cannot be directly related. Any plot with normalized parameter variation should include the values to which each parameter was normalized ${ }^{\text {. }}$

Due to the ongoing development of best practices for measuring $J-V$ curves and efficiency of PSCs ${ }^{28-31,110}$, the procedure for making periodic measurements during ageing tests should be clearly described. Typically, measurements of the $J-V$ curve (or parts thereof) are made with a periodicity that depends on the characteristic degradation timescale of each given device. Because $J-V$ hysteresis is common in PSCs, steps should be taken to ensure that the measurements are taken under (quasi) steady-state conditions. This can usually be done by using a dynamic $J-V$ approach $^{29,111}$, which allows time at each voltage step for the current to settle (stabilize), or, alternatively, by using a very slow $J-V$ scan in the vicinity of the MPP, usually repeated in the reverse direction to check for consistency. If suitable equipment is available, a third approach to logging the steady-state performance of the device over time is MPP tracking (MPPT) ${ }^{6,30,35}$. MPPT simultaneously holds the device at its normal operating voltage and measures the output. However, due to hysteresis, standard perturb and observe MPPT algorithms might be suboptimal for PSCs ${ }^{112}$. Modifications of a perturb and observe algorithm were suggested for effective MPPT in solar cells exhibiting hysteresis, including extended thresholds for switching the voltage sweep direction ${ }^{112}$ and predictive MPPT algorithms with lowered settling times ${ }^{13,114}$.If any form of MPPT is used during an experiment, the hardware and MPPT algorithm should be clearly referenced. Similar to organic solar cells ${ }^{115}$, preconditioning the PSC (with light and/or electrical bias) prior to each $J-V$ scan may affect the outcome and should be reported.

MPPT is also recommended as a bias condition for ageing experiments done under illumination (mandatory only at the third sophistication level). When MPPT is performed throughout the entire ageing test, it is recommended to periodically measure $J-V$ curves, because such measurements provide information on the degradation mechanism that is more detailed. Additional nondestructive characterizations at the intermediate stages of PSC ageing are also encouraged, although care must be taken to account for possible cell recovery during the measurement.

Ideally, light sources with an irradiance of $800-1000 \mathrm{~W} \mathrm{~m}^{-2}$ ( 1 sun $=1000 \mathrm{~W} \mathrm{~m}^{-2}$ ) should be applied, and the exact irradiance, the type of light source and its spectrum should be reported. Table 4 shows a collection of the most stable reported PSCs to date that can withstand over $1000 \mathrm{~h}$ of light-soaking while losing $<15 \%$ of their initial PCE. Five main types of light sources were used: sulfur plasma lamp, white light-emitting diodes (LEDs), metal halide xenon lamp, solar simulator and outdoor (that is, real sunlight). The solar simulator section encompasses devices analysed under unspecified conditions of irradiation. Sulfur plasma and white LED illumination typically do not include UV light, so it is redundant to report the use (or not) of a UV filter (except for some modern LED sources with extended range, which may have components in the range $300-400 \mathrm{~nm}$ ); in fact, reporting that "no UV filter was applied" would be misleading in this case. Metal halide and xenon arc lamps have UV light in their spectra, so any filtering used must be reported. Reporting the company and model of the solar simulator is good practice. Note that ASTM's class 'A' for simulated solar spectrum is only relevant in the range $400-1100 \mathrm{~nm}^{116}$. Therefore, the type of light source used and its spectrum should always be clearly specified. For example, 


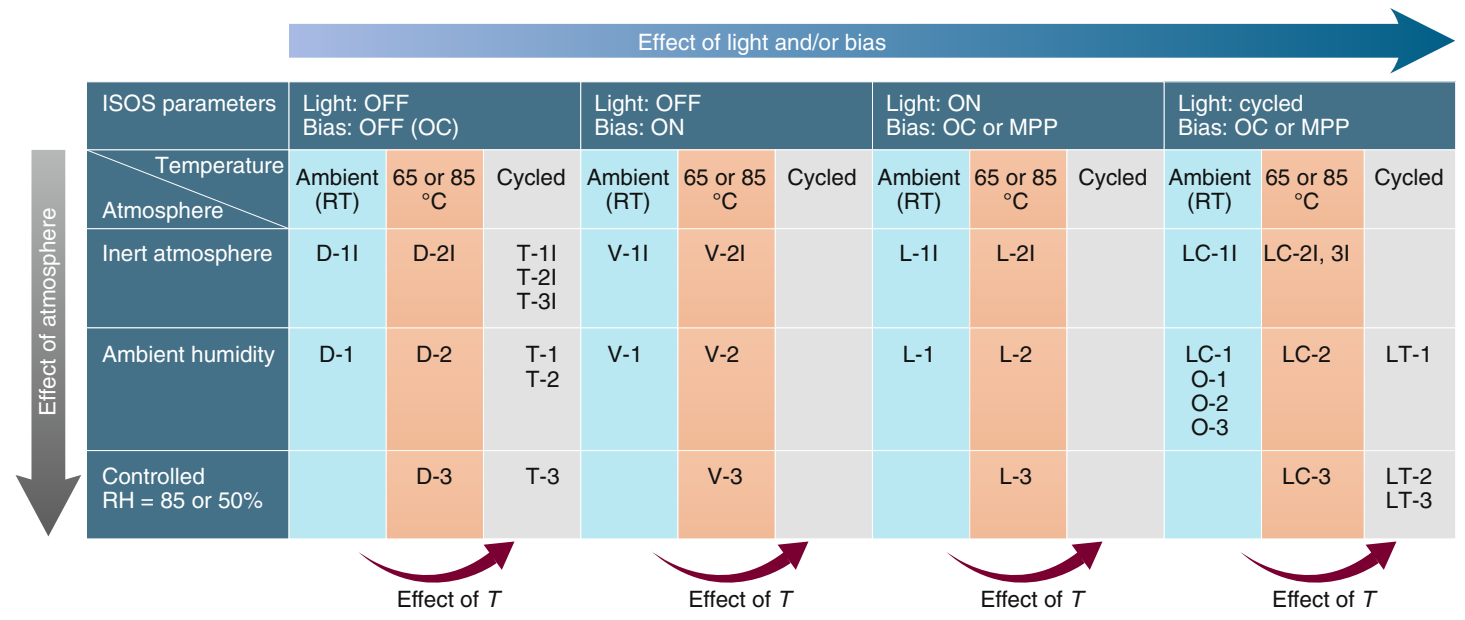

Fig. 3 | Stress factors affecting solar cells in different ISOS protocols. Rows correspond to different atmospheres, columns correspond to different combinations of light and electrical bias, and sub-columns depict different temperature regimes. Arrows alongside the table guide the eye for comparing protocols to identify the effects of atmosphere, temperature, light or electrical bias.

reporting 'AM $1.5 \mathrm{G}$ illumination' without specifying the light source, the solar simulator details and the calibration procedure, is not sufficient.

Furthermore, some of the light sources described above (especially xenon lamps) may degrade significantly on the timescale of stability experiments, so it is recommended to periodically check the light intensity with a reference cell.

Several reports claim that PSCs, as well as DSSCs ${ }^{117,118}$ and organic solar cells ${ }^{119-122}$, might be suitable for indoor and outdoor low-light-intensity applications ${ }^{123,124}$. Indoor-light illuminance is significantly lower (100 to 200 lux in a typical home, and 250 to 1000 lux in an office ${ }^{125}$, which corresponds to $\sim 0.01$ sun irradiance). The spectra of indoor-light sources also differ significantly from natural sunlight, and there is still no standard spectrum for indoor PV testing ${ }^{126,127}$. The share of LEDs in the indoor lighting market is expected to increase due to their high lighting efficiency ${ }^{128}$. For PSCs intended for low-intensity illumination, we encourage device characterization at several intensity levels (for example, 200, 500, 1000 lux) and reporting the light source (preferably LED) spectrum in accordance with the original ISOS procedures ${ }^{11}$.

\section{Stability figures of merit and acceleration factors}

The time required to drop to $80 \%$ of the initial efficiency is commonly denoted $T_{80}$ and often serves as a figure of merit for solar cell stability. It would, therefore, be an optimal minimum ageing test time. Extrapolation of degradation data (or readily achieved $T_{80}$ lifetimes) can be used to evaluate the cell lifetime energy yield ${ }^{129}$, which is an important parameter for calculating return on investment and life cycle analysis. Despite the apparent simplicity, there are several approaches ${ }^{129,130}$ to determine $T_{80}$ for devices (see Fig. 2 and Table 5 for a summary). Figure 2 explains three approaches for calculating $T_{80}$, which are applicable to different ageing scenarios. It is, therefore, vital to detail the metrics used when reporting stability studies. In particular, the original ISOS protocols ${ }^{11}$ suggested the use of a 'stabilized $T_{80}$ time' (denoted $T_{580}$ ), which is the time during which the PCE decreases by $20 \%$ of its magnitude after an arbitrarily defined stabilization time (indicated in blue in Fig. 2f). This suggestion is based on the widely known shape of the 'PCE versus time' curve in OPVs, which reflects a rapid initial degradation ('burn-in') ${ }^{129}$ followed by a stabilized region. Although similar dynamics occur in some PSCs ${ }^{4,131,132}$, it is not a universal trend for these devices. Figure 2 shows various examples, including the nonmonotonic evolution of PCE with time.
For the most stable PSCs, $T_{80}$ exceeds $1000 \mathrm{~h}$ (42 days) or even $10000 \mathrm{~h}$ ( $>1$ year) for two dimensional (2D)-3D perovskites ${ }^{133}$ under certain stress conditions, including illumination (see Table 4). Considering recent advancements in PSC stability, we strongly recommend that reviewers and journal editors discourage the use of the word 'stable' in the title of scientific papers in an unspecific manner (thermal, photo-, operational, and so on) and without matching the state of the art for a specific device type. Notably, such long exposure times are challenging to realize. If $T_{80}$ is not reached, it is difficult to predict the lifetime based on the observed 'PCE versus time' trend because of the variety of possible curve shapes (see Fig. 2). In this case, we suggest ageing the sample for at least $1000 \mathrm{~h}$ and using the PCE after $1000 \mathrm{~h}$ of stress $\left(\eta_{1000}\right.$, as a percentage of the initial PCE) as the stability figure of merit. If researchers choose to apply any type of extrapolation to determine $T_{80}$ or $T_{580}$, it must be clearly differentiated from the measured data. We recommend limiting the extrapolation times to less than one order of magnitude beyond the actual ageing time. As PSC stability improves, it may become common to quote $T_{95}$, which is the time required to degrade to $95 \%$ of the initial efficiency. This will also be in accordance with the IEC procedures, where the pass criterion is for the modules, after exposure to stress, to operate at $>95 \%$ of their starting performance.

The presence of reversible degradation in PSCs makes it harder to assess their stability. Although no broadly accepted figures of merit currently exist to account for partial reversibility, some procedures are currently under debate ${ }^{8,74}$. Recovery effects can be studied in two types of experiments: continuous ageing followed by performance tracking after stress removal, or cycled stress experiments. In the former case, it was suggested to correct $T_{80}$ to account for the restoration done during the rest period ${ }^{8}$. In cycling experiments (such as ISOS-LC), an analogue of the $T_{80}$ metric might be introduced for the energy output per cycle ${ }^{74}$.

The ISOS testing protocols do not provide direct information on the expected lifetime of solar cells under operational conditions. For such evaluations, the concept of acceleration factor (AF) has been used $^{134}$. The AF is a constant that relates the times to failure in an accelerated stress test with that in a reference stress test. Once determined for an ageing protocol (and validated through real-world operation), the AF provides an estimate of the solar cell lifetime in a fast and reproducible manner in the laboratory. AF for each stress should, in principle, be derived from a physical model, such as the activation energy (that is, the Arrhenius factor) in thermal 
accelerated lifetime tests. To date, no reports have been made of AFs of PSCs subjected to accelerated ageing, but they should appear as the technology matures. For organic solar cells, more attempts have been made to deduce AFs for accelerated ageing ${ }^{42,134,135}$. AFs for most ISOS tests were determined relative to outdoor conditions in northern Europe using OPV mini modules ${ }^{134}$. Overall, dark-storage ISOS-D tests can yield AFs between 0.45 (ISOS-D-1) and 12 (ISOS-D-3). Light soaking ISOS-L tests gave an AF of 15 and 24 in ISOS-L-1 and ISOS-L-2, respectively.

To further ramp up the development of stable PSCs, some suggest using high-intensity light ${ }^{5,136-139}$, which has been used for degradation studies of perovskite absorbers ${ }^{136}$ and solar cells ${ }^{138}$ with intensities up to 100 and 10 suns, respectively. Rough estimates show that even moderate light intensities of several suns can tremendously accelerate the degradation. For example, a PV operating for $1000 \mathrm{~h}$ under continuous illumination with an intensity of only 5 suns under $85^{\circ} \mathrm{C}$ is estimated to provide an equivalent of tens of years of outdoor testing if degradation scales linearly with light intensity ${ }^{5}$. Such intensities are easily achievable with commercial light sources and solar concentration.

Although high light intensities (up to hundreds of suns) can provide substantially higher AFs, such tests require careful, independent control of the solar cell temperature and illumination intensity ${ }^{140,141}$. Moreover, care should be taken to check whether the same degradation mechanisms occur under high light intensity and under 1 sun. Such experiments were done for OPVs ${ }^{135,142,143}$ and predicted lifetimes in the range of tens of years ${ }^{143,144}$. To the best of our knowledge, no similar studies have yet been reported for PSCs.

\section{Protocols applications and outlook}

We suggest that future stability studies include at least one or, ideally, multiple ISOS tests with level 1 procedures being the minimum requirement for testing. Using the labelling we proposed would allow easy identification of the testing conditions used. We recommend reporting all the data indicated in Table 3 to foster transparency and reproducibility.

Getting a better understanding of solar cell failure modes is critical for PSCs as they are still at the early stage of technology development. The ISOS protocols we have discussed in the present article can be used to screen a variety of stressor combinations. Figure 3 summarizes the relationship between the protocols with the major currently known degradation factors for PSCs: atmosphere, temperature, electrical bias and light. For each combination of light and bias, nine types of ageing protocols might be suggested with respect to temperature (ambient, elevated or cycled) and atmosphere (inert, ambient or controlled humidity). Apart from determining device lifetime under specific conditions, the impact of the stress factors can be understood by comparing the results of different ageing procedures with each other. For example, comparing protocols D-1 and D-2 provides insight on the effect of elevated temperature, comparing protocols D-2I, D-2, and D-3 provides insights on the effect of the atmosphere, comparing protocols D-2 and L-2 provides insights on the combined effect of light and heat, and so on. The arrows in Fig. 3 schematically depict these relationships.

The blank spaces in Fig. 2 can be filled with the corresponding ageing procedures (by analogy with the additional ISOS tests we have suggested in this Consensus Statement). Other protocols can be constructed by varying the 'fixed' parameters (for example, temperature, light intensity, RH). We do not aim to cover all possibilities with the ISOS protocols nor discredit studies with a systematic variation of a particular stressor. Nevertheless, these investigations would benefit from having common 'reference points' with other studies conducted at different laboratories, with different device architectures, different perovskite materials and even different research questions. Consensual conditions, like ISOS protocols, may serve as such references.
Unified procedures for stability studies and consistency in data reporting could lead to the creation of a large machine-readable database on PSC stability. Machine learning (ML) methods ${ }^{145-147}$ could potentially identify patterns in such data, detect statistically significant stress factors, correlate repeated phenomena in different studies to detect universal degradation mechanisms and stabilizing approaches, and predict lifetimes and failure modes. Information from ageing measurements under the relevant stressors can optimize the steps required for supervised learning algorithms. Ultimately, ML relies heavily on having sufficient quantity and diversity of information from ageing tests to provide an accurate prediction of device performance and degradation. Thus, ML algorithms must be trained with extensive laboratory data so that predictions can be compared with actual performance measurements. Once working, ML tools should provide knowledge extraction without the need to do all the tests in Fig. 3.

To accommodate the large number of perovskites possibly suitable for PV, a shared-knowledge repository database has been proposed $^{145}$, where positive and negative results from stability tests are considered equally important for ML (that is, not only the champion cell but also the suboptimal or underperforming cells aged under similar conditions), because they all represent valuable training data. It is therefore critical that a trend emerges that all cells that undergo ageing tests are measured and reported for the duration, even total failures. At the laboratory scale, this information could be shared if researchers report the conditions used for device fabrication and testing through a common website. Progress in this direction might be significantly accelerated if researchers, who foresee their data being useful for ML, provide complete information (on device fabrication, performance and stability) in standardized tabulated format (a possible template is available in the Supplementary Information). A similar strategy can be extended from PSCs to other emerging PV systems.

\section{Conclusions}

We have presented our consensus on procedures for studying the stability of perovskite solar cells. The protocols we suggest primarily rely on the original ISOS standards developed for OPV cells ${ }^{11}$, which have proven to be highly relevant for uncovering various degradation pathways in PSCs. We have further extended the protocols with a set of testing procedures in accordance with specific stability features of PSCs, including light-dark cycling (ISOS-LC) mimicking the diurnal cycle, study of solar cell behaviour under continuously applied bias in the dark (ISOS-V) and protocols for studying intrinsic solar cell stability (indexed with 'I'). We have indicated which figures-of-merit for device stability should be used to take into account the evolution of the PSC performance over time. To improve reproducibility, we also propose a checklist for reporting results from PSC stability studies more consistently.

We hope that the guidelines for conducting and reporting stability studies described in this paper will improve comparisons between data from different laboratories and from different device architectures. The set of procedures and practices suggested here serves as an intermediate stage in perovskite solar cell technology maturation, aimed at the identification of degradation pathways and the prospects for their mitigation.

\section{Methods}

The work extends the outcomes of the round table discussion on PSC stability assessment that took place during the 11th International Summit on Organic and Hybrid Photovoltaics Stability (ISOS 11) in Suzhou, China, in October 2018 (http:// isos11.csp.escience.cn/dct/page/1) The round table was followed by drafting of the discussed procedures and manuscript text, which were circulated between the contributing authors multiple times until a consensus was reached among the authors. In cases when no single opinion was possible between all the co-authors we extended the number of options presented. 
Received: 24 May 2019; Accepted: 27 November 2019; Published online: 22 January 2020

\section{References}

1. IEC 61215-1:2016 Terrestrial Photovoltaic (PV) Modules - Design Qualification and Type Approval - Part 1: Test Requirements (IEC Webstore, 2016); https://webstore.iec.ch/publication/24312

2. IEC 61215-2:2016 Terrestrial Photovoltaic (PV) Modules - Design Qualification and Type Approval - Part 2: Test Procedures (IEC Webstore, 2016); https://webstore.iec.ch/publication/24311

3. Nanotechnology - reliability assessment - part 2.1: nano-enabled photovoltaic - stability test. StatNano https://statnano.com/standard/ iec/1223 (2016).

4. Domanski, K., Alharbi, E. A., Hagfeldt, A., Grätzel, M. \& Tress, W. Systematic investigation of the impact of operation conditions on the degradation behaviour of perovskite solar cells. Nat. Energy 3, 61 (2018).

5. Boyd, C. C., Cheacharoen, R., Leijtens, T. \& McGehee, M. D. Understanding degradation mechanisms and improving stability of perovskite photovoltaics. Chem. Rev. 119, 3418-3451 (2018).

6. Abate, A., Correa-Baena, J.-P., Saliba, M., Su'ait, M. S. \& Bella, F. Perovskite solar cells: from the laboratory to the assembly line. Chemistry $\mathbf{2 4}$ 3083-3100 (2018).

7. Christians, J. A., Habisreutinger, S. N., Berry, J. J. \& Luther, J. M. Stability in perovskite photovoltaics: a paradigm for newfangled technologies. ACS Energy Lett. 3, 2136-2143 (2018).

8. Saliba, M., Stolterfoht, M., Wolff, C. M., Neher, D. \& Abate, A. Measuring ageing stability of perovskite solar cells. Joule 2, 1019-1024 (2018).

9. Saliba, M. Perovskite solar cells must come of age. Science 359, 388-389 (2018).

10. Snaith, H. J. \& Hacke, P. Enabling reliability assessments of pre-commercial perovskite photovoltaics with lessons learned from industrial standards. Nat. Energy 3, 459-465 (2018).

11. Reese, M. O. et al. Consensus stability testing protocols for organic photovoltaic materials and devices. Sol. Energy Mater. Sol. Cells $\mathbf{9 5}$, 1253-1267 (2011).

12. Gevorgyan, S. A. et al. An inter-laboratory stability study of roll-to-roll coated flexible polymer solar modules. S Sol. Energy Mater. Sol. Cells 95 , 1398-1416 (2011)

13. Madsen, M. V. et al. Worldwide outdoor round robin study of organic photovoltaic devices and modules. Sol. Energy Mater. Sol. Cells 130, 281-290 (2014).

14. Tanenbaum, D. M. et al. The ISOS-3 inter-laboratory collaboration focused on the stability of a variety of organic photovoltaic devices. RSC Adv. 2, 882-893 (2012).

15. Best Research-Cell Efficiency Chart (NREL, 2019); https://www.nrel.gov/pv/ cell-efficiency.html.

16. Green, M. A. et al. Solar cell efficiency tables (version 54). Prog. Photovolt. 27, 565-575 (2019).

17. Lang, Felix et al. Influence of radiation on the properties and the stability of hybrid perovskites. Adv. Mater. 30, 1702905 (2017).

18. Lee, S.-W. et al. UV degradation and recovery of perovskite solar cells. Sci. Rep. 6, srep38150 (2016).

19. Kim, N.-K. et al. Investigation of thermally induced degradation in $\mathrm{CH}_{3} \mathrm{NH}_{3} \mathrm{PbI}_{3}$ perovskite solar cells using in-situ synchrotron radiation analysis. Sci. Rep. 7, 4645 (2017).

20. Schwenzer, J. A. et al. Temperature variation induced performance decline of perovskite solar cells. ACS Appl. Mater. Interfaces 10, 16390-16399 (2018).

21. Holzhey, P. et al. A chain is as strong as its weakest link - stability study of MAPbI3 under light and temperature. Mater. Today 29, 10-19 (2018).

22. Yang, J., Siempelkamp, B. D., Liu, D. \& Kelly, T. L. Investigation of $\mathrm{CH}_{3} \mathrm{NH}_{3} \mathrm{PbI}_{3}$ degradation rates and mechanisms in controlled humidity environments using in situ techniques. ACS Nano 9, 1955-1963 (2015).

23. Bryant, D. et al. Light and oxygen induced degradation limits the operational stability of methylammonium lead triiodide perovskite solar cells. Energy Environ. Sci. 9, 1655-1660 (2016).

24. Howard, J. M. et al. Humidity-induced photoluminescence hysteresis in variable $\mathrm{Cs} / \mathrm{Br}$ ratio hybrid perovskites. J. Phys. Chem. Lett. 9 3463-3469 (2018)

25. Khenkin, M. V., Anoop, K. M., Katz, E. \& Visoly-Fisher, I. Bias-dependent degradation of various solar cells: lessons for stability of perovskite photovoltaics. Energy Environ. Sci. 12, 550-558 (2019).

26. Bae, S. et al. Electric-field-induced degradation of methylammonium lead iodide perovskite solar cells. J. Phys. Chem. Lett. 7, 3091-3096 (2016).

27. Tiihonen, A. et al. Critical analysis on the quality of stability studies of perovskite and dye solar cells. Energy Environ. Sci. 11, 730-738 (2018).

28. Report on Measurement and Stability Testing Protocols (CHEOPS, 2018); https://cloud.accelopment.com/index.php/s/FXmakKn5qXxzYea\#pdfviewer
29. Dunbar, R. B. et al. How reliable are efficiency measurements of perovskite solar cells? the first inter-comparison, between two accredited and eight non-accredited laboratories. J. Mater. Chem. A 5, 22542-22558 (2017).

30. Christians, J. A., Manser, J. S. \& Kamat, P. V. Best practices in perovskite solar cell efficiency measurements. avoiding the error of making bad cells look good. J. Phys. Chem. Lett. 6, 852-857 (2015).

31. IEC TR 63228 ED1 | Measurement protocols for photovoltaic devices based on organic, dye-sensitized or perovskite materials (IEC, 2019).

32. Yang, Y. \& You, J. Make perovskite solar cells stable. Nature 544, 155 (2017).

33. Meng, L., You, J. \& Yang, Y. Addressing the stability issue of perovskite solar cells for commercial applications. Nat. Commun. 9, 5265 (2018).

34. Tress, W. et al. Understanding the rate-dependent J-V hysteresis, slow time component, and ageing in $\mathrm{CH} 3 \mathrm{NH} 3 \mathrm{PbI} 3$ perovskite solar cells: the role of a compensated electric field. Energy Environ. Sci. 8, 995-1004 (2015).

35. L. Unger, E. et al. Hysteresis and transient behavior in current-voltage measurements of hybrid-perovskite absorber solar cells. Energy Environ. Sci. 7, 3690-3698 (2014).

36. Jena, A. K., Kulkarni, A., Ikegami, M. \& Miyasaka, T. Steady state performance, photo-induced performance degradation and their relation to transient hysteresis in perovskite solar cells. J. Power Sources 309 1-10 (2016).

37. Leguy, A. M. A. et al. Reversible hydration of $\mathrm{CH}_{3} \mathrm{NH}_{3} \mathrm{PbI}_{3}$ in films, single crystals, and solar cells. Chem. Mater. 27, 3397-3407 (2015).

38. Noh, J. H., Im, S. H., Heo, J. H., Mandal, T. N. \& Seok, S. I. Chemical management for colorful, efficient, and stable inorganic-organic hybrid nanostructured solar cells. Nano Lett. 13, 1764-1769 (2013).

39. Lee, H., Lee, C. \& Song, H.-J. Influence of electrical traps on the current density degradation of inverted perovskite solar cells. Materials (Basel) 12, 1644 (2019).

40. Pearson, A. J. et al. Oxygen degradation in mesoporous $\mathrm{Al}_{2} \mathrm{O}_{3} / \mathrm{CH}_{3} \mathrm{NH}_{3} \mathrm{PbI}_{3}$ ${ }_{x} \mathrm{Cl}_{x}$ perovskite solar cells: kinetics and mechanisms. Adv. Energy Mater. 6, 1600014 (2016).

41. Anaya, M., Galisteo-López, J. F., Calvo, M. E., Espinós, J. P. \& Míguez, H. Origin of light-induced photophysical effects in organic metal halide perovskites in the presence of oxygen. J. Phys. Chem. Lett. 9, 3891-3896 (2018)

42. Haillant, O., Dumbleton, D. \& Zielnik, A. An Arrhenius approach to estimating organic photovoltaic module weathering acceleration factors. Sol. Energy Mater. Sol. Cells 95, 1889-1895 (2011).

43. Divitini, G. et al. In situ observation of heat-induced degradation of perovskite solar cells. Nat. Energy 1, 15012 (2016).

44. Abate, A. et al. Silolothiophene-linked triphenylamines as stable hole transporting materials for high efficiency perovskite solar cells. Energy Environ. Sci. 8, 2946-2953 (2015)

45. Malinauskas, T. et al. Enhancing thermal stability and lifetime of solid-state dye-sensitized solar cells via molecular engineering of the hole-transporting material spiro-OMeTAD. ACS Appl. Mater. Interfaces 7, 11107-11116 (2015)

46. Onoda-Yamamuro, N., Matsuo, T. \& Suga, H. Calorimetric and IR spectroscopic studies of phase transitions in methylammonium trihalogenoplumbates (II)†. J. Phys. Chem. Solids 51, 1383-1395 (1990).

47. Röhm, H. et al. Ferroelectric properties of perovskite thin films and their implications for solar energy conversion. Adv. Mater. 0, 1806661 (2019).

48. Song, Z. et al. Perovskite solar cell stability in humid air: partially reversible phase transitions in the $\mathrm{PbI}_{2}-\mathrm{CH}_{3} \mathrm{NH}_{3} \mathrm{I}-\mathrm{H}_{2} \mathrm{O}$ system. Adv. Energy Mater. 6 , 1600846 (2016).

49. Christians, J. A. et al. Tailored interfaces of unencapsulated perovskite solar cells for $>1,000$ hour operational stability. Nat. Energy 3, 68 (2018).

50. Gottesman, R. et al. Extremely slow photoconductivity response of $\mathrm{CH}_{3} \mathrm{NH}_{3} \mathrm{PbI}_{3}$ perovskites suggesting structural changes under working conditions. J. Phys. Chem. Lett. 5, 2662-2669 (2014).

51. Domanski, K. et al. Migration of cations induces reversible performance losses over day/night cycling in perovskite solar cells. Energy Environ. Sci. 10, 604-613 (2017).

52. Cacovich, S. et al. Gold and iodine diffusion in large area perovskite solar cells under illumination. Nanoscale 9, 4700-4706 (2017).

53. Deng, X. et al. Dynamic study of the light soaking effect on perovskite solar cells by in-situ photoluminescence microscopy. Nano Energy 46, 356-364 (2018)

54. Duong, T. et al. Light and elevated temperature induced degradation (LeTID) in perovskite solar cells and development of stable semitransparent cells. Sol. Energy Mater. Sol. Cells 188, 27-36 (2018).

55. Hoke, E. T. et al. Reversible photo-induced trap formation in mixed-halide hybrid perovskites for photovoltaics. Chem. Sci. 6 613-617 (2015).

56. Duong, T. et al. Light and electrically induced phase segregation and its impact on the stability of quadruple cation high bandgap perovskite solar cells. ACS Appl. Mater. Interfaces 9, 26859-26866 (2017). 
57. Ceratti, D. R. et al. Self-healing inside $\mathrm{APbBr}_{3}$ halide perovskite crystals Adv. Mater. 30, 1706273 (2018)

58. Nie, W. et al. Light-activated photocurrent degradation and self-healing in perovskite solar cells. Nat. Commun. 7, 11574 (2016).

59. Lira-Cantú, M. Perovskite solar cells: stability lies at interfaces. Nat. Energy 2, 17115 (2017)

60. Domanski, K. et al. Not all that glitters is gold: metal-migration-induced degradation in perovskite solar cells. ACS Nano 10, 6306-6314 (2016).

61. Akbulatov, A. F. et al. Effect of electron-transport material on light-induced degradation of inverted planar junction perovskite solar cells. Adv. Energy Mater. 7, 1700476 (2017)

62. Kettle, J. et al. Printable luminescent down shifter for enhancing efficiency and stability of organic photovoltaics. Sol. Energy Mater. Sol. Cells 144, 481-487 (2016).

63. Gonzalez-Valls, I. \& Lira-Cantu, M. Dye sensitized solar cells based on vertically-aligned $\mathrm{ZnO}$ nanorods: effect of UV light on power conversion efficiency and lifetime. Energy Environ. Sci. 3, 789-795 (2010).

64. Melvin, A. A. et al. Lead iodide as a buffer layer in UV-induced degradation of $\mathrm{CH}_{3} \mathrm{NH}_{3} \mathrm{PbI}_{3}$ films. Sol. Energy 159, 794-799 (2018).

65. Leijtens, T. et al. Overcoming ultraviolet light instability of sensitized $\mathrm{TiO}_{2}$ with meso-superstructured organometal tri-halide perovskite solar cells. Nat. Commun. 4, 2885 (2013).

66. Shin, S. S. et al. Colloidally prepared La-doped $\mathrm{BaSnO}_{3}$ electrodes for efficient, photostable perovskite solar cells. Science 356, 167-171 (2017).

67. Pérez-Tomas, A. et al. $\mathrm{PbZrTiO}_{3}$ ferroelectric oxide as an electron extraction material for stable halide perovskite solar cells. Sustain. Energy Fuels 3, 382-389 (2019).

68. Farooq, A. et al. Spectral dependence of degradation under ultraviolet light in perovskite solar cells. ACS Appl. Mater. Interfaces 10, 21985-21990 (2018)

69. Osterwald, C. R. \& McMahon, T. J. History of accelerated and qualification testing of terrestrial photovoltaic modules: a literature review. Prog. Photovolt. 17, 11-33 (2009).

70. Rosenthal, A. L., Thomas, M. G. \& Durand, S. J. A ten year review of performance of photovoltaic systems. in Conference Record of the Twenty Third IEEE Photovoltaic Specialists Conference - 1993 (Cat. No.93CH3283-9) 1289-1291 (1993). https://doi.org/10.1109/PVSC.1993.346934.

71. Kurtz, S. et al. A framework for a comparative accelerated testing standard for PV modules. In Proc. 2013 IEEE 39th Photovoltaic Specialists Conference (PVSC) 0132-0138 (IEEE, 2013).

72. $\mathrm{Li}, \mathrm{X}$. et al. Outdoor performance and stability under elevated temperatures and long-term light soaking of triple-layer mesoporous perovskite photovoltaics. Energy Technol. 3, 551-555 (2015).

73. Reyna, Y. et al. Performance and stability of mixed $\mathrm{FAPbI}_{3(0.85)} \mathrm{MAPbBr}_{3(0.15)}$ halide perovskite solar cells under outdoor conditions and the effect of low light irradiation. Nano Energy 30, 570-579 (2016).

74. Khenkin, M. V. et al. Reconsidering figures of merit for performance and stability of perovskite photovoltaics. Energy Environ. Sci. 11, 739-743 (2018).

75. Stoichkov, V. et al. Outdoor performance monitoring of perovskite solar cell mini-modules: diurnal performance, observance of reversible degradation and variation with climatic performance. Sol. Energy 170, 549-556 (2018).

76. Tan, H. et al. Efficient and stable solution-processed planar perovskite solar cells via contact passivation. Science 355, 722-726 (2017).

77. Cheacharoen, R. et al. Design and understanding of encapsulated perovskite solar cells to withstand temperature cycling. Energy Environ. Sci. 11, 144-150 (2018).

78. Holzhey, P. \& Saliba, M. A full overview of international standards assessing the long-term stability of perovskite solar cells. J. Mater. Chem. A 6, 21794-21808 (2018).

79. Tress, W. et al. Performance of perovskite solar cells under simulated temperature-illumination real-world operating conditions. Nat. Energy 4, 568-574 (2019).

80. Bag, M. et al. Kinetics of ion transport in perovskite active layers and its implications for active layer stability. J. Am. Chem. Soc. 137, 13130-13137 (2015).

81. Khenkin, M. V. et al. Dynamics of photoinduced degradation of perovskite photovoltaics: from reversible to irreversible processes. ACS Appl. Energy Mater. 1, 799-806 (2018).

82. Huang, F. et al. Fatigue behavior of planar $\mathrm{CH}_{3} \mathrm{NH}_{3} \mathrm{PbI}_{3}$ perovskite solar cells revealed by light on/off diurnal cycling. Nano Energy 27, 509-514 (2016).

83. Jiang, L. et al. Fatigue stability of $\mathrm{CH} 3 \mathrm{NH} 3 \mathrm{PbI} 3$ based perovskite solar cells in day/night cycling. Nano Energy 58, 687-694 (2019).

84. Zhao, C. et al. Perovskite solar cells: revealing underlying processes involved in light soaking effects and hysteresis phenomena in perovskite solar cells Adv. Energy Mater. 5, 1500279 (2015).

85. Garrett, J. L. et al. Real-time nanoscale open-circuit voltage dynamics of perovskite solar cells. Nano Lett. 17, 2554-2560 (2017).
86. Tennyson, E. M. et al. Cesium-incorporated triple cation perovskites deliver fully reversible and stable nanoscale voltage response. ACS Nano 13, 1538-1546 (2019).

87. Luchkin, S. Yu et al. Reversible and irreversible electric field induced morphological and interfacial transformations of hybrid lead iodide perovskites. ACS Appl. Mater. Interfaces 9, 33478-33483 (2017).

88. Bowring, A. R., Bertoluzzi, L., O'Regan, B. C. \& McGehee, M. D. Reverse bias behavior of halide perovskite solar cells. Adv. Energy Mater. 8, 1702365 (2018).

89. Barbé, J. et al. Dark electrical bias effects on moisture-induced degradation in inverted lead halide perovskite solar cells measured by using advanced chemical probes. Sustain. Energy Fuels 2, 905-914 (2018).

90. Chen, B. et al. Synergistic effect of elevated device temperature and excess charge carriers on the rapid light-induced degradation of perovskite solar cells. Adv. Mater. 31, 1902413 (2019).

91. Leijtens, T. et al. Mapping electric field-induced switchable poling and structural degradation in hybrid lead halide perovskite thin films. Adv. Energy Mater. 5, 1500962 (2015).

92. Deng, X. et al. Electric field induced reversible and irreversible photoluminescence responses in methylammonium lead iodide perovskite. J. Mater. Chem. C. 4, 9060-9068 (2016).

93. Kersten, F. et al. Degradation of multicrystalline silicon solar cells and modules after illumination at elevated temperature. Sol. Energy Mater. Sol. Cells 142, 83-86 (2015).

94. Seyedmahmoudian, M. et al. Simulation and hardware implementation of new maximum power point tracking technique for partially shaded PV system using hybrid DEPSO method. IEEE Trans. Sustain. Energy $\mathbf{6}$, 850-862 (2015).

95. Rajagopal, A., Williams, S. T., Chueh, C.-C. \& Jen, A. K.-Y. Abnormal current-voltage hysteresis induced by reverse bias in organicinorganic hybrid perovskite photovoltaics. J. Phys. Chem. Lett. 7, 995-1003 (2016)

96. Nisato, G. et al. Experimental comparison of high-performance water vapor permeation measurement methods. Org. Electron. 15, 3746-3755 (2014).

97. Paetzold, R., Winnacker, A., Henseler, D., Cesari, V. \& Heuser, K. Permeation rate measurements by electrical analysis of calcium corrosion. Rev. Sci. Instrum. 74, 5147-5150 (2003).

98. Reese, M. O., Dameron, A. A. \& Kempe, M. D. Quantitative calcium resistivity based method for accurate and scalable water vapor transmission rate measurement. Rev. Sci. Instrum. 82, 085101 (2011).

99. Ultra-High Barrier Properties Are Finally Measurable (Fraunhofer, 2013); https://www.encapsulation.fraunhofer.de/content/dam/fleet/de/documents/ SEMPA/Datenblatt\%20HiBarSens.pdf

100. Klumbies, H., Müller-Meskamp, L., Mönch, T., Schubert, S. \& Leo, K. The influence of laterally inhomogeneous corrosion on electrical and optical calcium moisture barrier characterization. Rev. Sci. Instrum. 84 024103 (2013).

101. Boldrighini, P. et al. Optical calcium test for measurement of multiple permeation pathways in flexible organic optoelectronic encapsulation. Rev. Sci. Instrum. 90, 014710 (2019).

102. Uddin, A., Upama, M. B., Yi, H. \& Duan, L. Encapsulation of organic and perovskite solar cells: a review. Coatings 9, 65 (2019).

103. Cheacharoen, R. et al. Encapsulating perovskite solar cells to withstand damp heat and thermal cycling. Sustain. Energy Fuels 2, 2398-2406 (2018)

104. Li, B., Wang, M., Subair, R., Cao, G. \& Tian, J. Significant stability enhancement of perovskite solar cells by facile adhesive encapsulation. J. Phys. Chem. C. 122, 25260-25267 (2018).

105. Matteocci, F. et al. Encapsulation for long-term stability enhancement of perovskite solar cells. Nano Energy 30, 162-172 (2016).

106. Akbulatov, A. F. et al. Probing the intrinsic thermal and photochemical stability of hybrid and inorganic lead halide perovskites. J. Phys. Chem. Lett. 8, 1211-1218 (2017)

107. Conings, B. et al. Intrinsic thermal instability of methylammonium lead trihalide perovskite. Adv. Energy Mater. 5, 1500477 (2015).

108. Yang, J. et al. Photostability of perovskite solar cells: unraveling photostability of mixed cation perovskite films in extreme environment. Adv. Opt. Mater. 6, 1870080 (2018)

109. A solar checklist. Nat. Photonics 9, 703 (2015).

110. Czudek, A. et al. Transient Analysis during maximum power point tracking (TRAMPPT) to assess dynamic response of perovskite solar cells. Preprint at https://arxiv.org/abs/1906.05028 (2019).

111. C. Monokroussos et al. Accurate power measurements of high capacitance pv modules with short pulse simulators in a single flash. In Proc. 27th European Photovoltaic Solar Energy Conference and Exhibition 3687-3692 (EUPVSEC, 2012).

112. Pellet, N. et al. Hill climbing hysteresis of perovskite-based solar cells: a maximum power point tracking investigation. Prog. Photovolt. 25, 942-950 (2017). 
113. Cimaroli, A. J. et al. Tracking the maximum power point of hysteretic perovskite solar cells using a predictive algorithm. J. Mater. Chem. C. 5, 10152-10157 (2017).

114. Bliss, M. et al. I-V performance characterisation of perovskite solar cells. In Proc. Photovoltaic Science, Applications and Technology (PVSAT-14) 5-8 (The Solar Energy Society, 2018).

115. Dusza, M., Strek, W. \& Granek, F. Significance of light-soaking effect in proper analysis of degradation dynamics of organic solar cells. JPE $\mathbf{6}$, 035503 (2016)

116. Emery, K. A. Solar simulators and I-V measurement methods. Sol. Cells 18, 251-260 (1986)

117. Freitag, M. et al. Dye-sensitized solar cells for efficient power generation under ambient lighting. Nat. Photonics 11, 372-378 (2017).

118. De Rossi, F., Pontecorvo, T. \& Brown, T. M. Characterization of photovoltaic devices for indoor light harvesting and customization of flexible dye solar cells to deliver superior efficiency under artificial lighting. Appl. Energy 156, 413-422 (2015).

119. Steim, R. et al. Organic photovoltaics for low light applications. Sol. Energy Mater. Sol. Cells 95, 3256-3261 (2011).

120. Lee, H. K. H., Li, Z., Durrant, J. R. \& Tsoi, W. C. Is organic photovoltaics promising for indoor applications? Appl. Phys. Lett. 108, 253301 (2016)

121. Yang, S.-S., Hsieh, Z.-C., Keshtov, M. L., Sharma, G. D. \& Chen, F.-C. Toward high-performance polymer photovoltaic devices for low-power indoor applications. Sol. RRL 1, 1700174 (2017).

122. Lee, H. K. H. et al. Organic photovoltaic cells - promising indoor light harvesters for self-sustainable electronics. J. Mater. Chem. A 6 5618-5626 (2018).

123. Chen, C.-Y. et al. Perovskite photovoltaics for dim-light applications. $A d v$ Funct. Mater. 25, 7064-7070 (2015)

124. Lucarelli, G., Di Giacomo, F., Zardetto, V., Creatore, M. \& Brown, T. M. Efficient light harvesting from flexible perovskite solar cells under indoor white light-emitting diode illumination. Nano Res. 10, 2130-2145 (2017).

125. ISO 8995-1:2002(en), Lighting of work places - Part 1: Indoor. ISO https://www.iso.org/obp/ui/\#iso:std:iso:8995:-1:ed-1:v1:en (2002).

126. Minnaert, B. \& Veelaert, P. A Proposal for typical artificial light sources for the characterization of indoor photovoltaic applications. Energies 7, 1500-1516 (2014).

127. Li, Y., Grabham, N. J., Beeby, S. P. \& Tudor, M. J. The effect of the type of illumination on the energy harvesting performance of solar cells. Sol. Energy 111, 21-29 (2015).

128. Curtis, D. Predictions for the contribution of residential lighting to the carbon emissions of the UK to 2050. In Proc. EEDAL Conference (2009); https://www.eci.ox.ac.uk/publications/downloads/curtis-EEDAL09.pdf

129. Roesch, R. et al. Procedures and practices for evaluating thin-film solar cell stability. Adv. Energy Mater. 5, 1501407 (2015).

130. Wang, Z. et al. Efficient and air-stable mixed-cation lead mixed-halide perovskite solar cells with n-doped organic electron extraction layers. $A d v$ Mater. 29, 1604186 (2017).

131. Arora, N. et al. Perovskite solar cells with CuSCN hole extraction layers yield stabilized efficiencies greater than 20\%. Science 358, 768-771 (2017).

132. Saliba, M. et al. Cesium-containing triple cation perovskite solar cells: improved stability, reproducibility and high efficiency. Energy Environ. Sci. 9, 1989-1997 (2016).

133. Grancini, G. et al. One-Year stable perovskite solar cells by $2 \mathrm{D} / 3 \mathrm{D}$ interface engineering. Nat. Commun. 8, 15684 (2017).

134. Kettle, J. et al. Using ISOS consensus test protocols for development of quantitative life test models in ageing of organic solar cells. Sol. Energy Mater. Sol. Cells 167, 53-59 (2017).

135. Burlingame, Q. et al. Reliability of small molecule organic photovoltaics with electron-filtering compound buffer layers. Adv. Energy Mater. 6, 1601094 (2016).

136. Misra, R. K. et al. Effect of halide composition on the photochemical stability of perovskite photovoltaic materials. ChemSusChem $\mathbf{9}$, 2572-2577 (2016).

137. Tan, W. et al. Initial photochemical stability in perovskite solar cells based on the $\mathrm{Cu}$ electrode and the appropriate charge transport layers. Synth. Met. 246, 101-107 (2018).

138. Wang, Z. et al. High irradiance performance of metal halide perovskites for concentrator photovoltaics. Nat. Energy 3, 855-861 (2018).

139. Misra, R. K. et al. Temperature- and component-dependent degradation of perovskite photovoltaic materials under concentrated sunlight. J. Phys. Chem. Lett. 6, 326-330 (2015).

140. Madsen, M. V., Tromholt, T., Norrman, K. \& Krebs, F. C. Concentrated light for accelerated photo degradation of polymer materials. Adv. Energy Mater. 3, 424-427 (2013)

141. Visoly-Fisher, I. et al. Concentrated sunlight for accelerated stability testing of organic photovoltaic materials: towards decoupling light intensity and temperature. Sol. Energy Mater. Sol. Cells 134, 99-107 (2015).
142. Züfle, S., Hansson, R., Katz, E. A. \& Moons, E. Initial photo-degradation of PCDTBT:PC70BM solar cells studied under various illumination conditions: Role of the hole transport layer. Sol. Energy 183, 234-239 (2019).

143. Burlingame, Q. C. Operational Stability And Charge Transport In FullereneBased Organic Solar Cells. PhD Thesis, The University of Michigan (2018).

144. Brabec, C. J. How to stabilize organic solar cells behind 100,000 hours of operational stability. Key-note talk at the 11th International Summit on Organic and Hybrid Photovoltaics Stability (ISOS11) (2018); https:// www.i-meet.ww.uni-erlangen.de/2018/10

145. Howard, J. M., Tennyson, E. M., Neves, B. R. A. \& Leite, M. S. Machine learning for perovskites' reap-rest-recovery cycle. Joule 3, 325-337 (2018).

146. Odabaşı, Ç. \& Yıldırım, R. Performance analysis of perovskite solar cells in 2013-2018 using machine-learning tools. Nano Energy 56, 770-791 (2019).

147. Saliba, M. Polyelemental, multicomponent perovskite semiconductor libraries through combinatorial screening. Adv. Energy Mater. 9, 1803754 (2019).

148. Bush, K. A. et al. 23.6\%-efficient monolithic perovskite/silicon tandem solar cells with improved stability. Nat. Energy 2, 17009 (2017).

149. Turren-Cruz, S.-H., Hagfeldt, A. \& Saliba, M. Methylammonium-free, high-performance, and stable perovskite solar cells on a planar architecture. Science 362, 449-453 (2018).

150. Bi, D. et al. Multifunctional molecular modulators for perovskite solar cells with over $20 \%$ efficiency and high operational stability. Nat. Commun. 9, 4482 (2018).

151. Hou, Y. et al. A generic interface to reduce the efficiency-stability-cost gap of perovskite solar cells. Science 358, 1192-1197 (2017)

152. Zhang, F. et al. Suppressing defects through the synergistic effect of a Lewis base and a Lewis acid for highly efficient and stable perovskite solar cells. Energy Environ. Sci. 11, 3480-3490 (2018)

153. Mei, A. et al. A hole-conductor-free, fully printable mesoscopic perovskite solar cell with high stability. Science 345, 295-298 (2014).

154. Bai, S. et al. Planar perovskite solar cells with long-term stability using ionic liquid additives. Nature 571, 245-250 (2019).

155. Chen, W. et al. Efficient and stable large-area perovskite solar cells with inorganic charge extraction layers. Science 350, 944-948 (2015).

156. Shang, R. et al. Disodium benzodipyrrole sulfonate as neutral holetransporting materials for perovskite solar cells. J. Am. Chem. Soc. 140, 5018-5022 (2018)

157. Tsai, H. et al. High-efficiency two-dimensional Ruddlesden-Popper perovskite solar cells. Nature 536, 312-316 (2016).

158. Luo, Q. et al. All-carbon-electrode-based endurable flexible perovskite solar cells. Adv. Funct. Mater. 28, 1706777 (2018).

\section{Acknowledgements}

This article is based upon work from COST Action StableNextSol MP1307 supported by COST (European Cooperation in Science and Technology). M.V.K., E.A.K., V.B. and A.O. thank the financial support of the United States - Israel Binational Science Foundation (grant no. 2015757). E.A.K., A.A. and I.V.-F. acknowledge partial support from the SNaPSHoTs project in the framework of the German-Israeli bilateral R\&D cooperation in the field of applied nanotechnology. M.S.L. thanks the financial support of National Science Foundation (ECCS, award \#1610833). S.C., M.Manceau and M.Matheron thank the financial support of European Union's Horizon 2020 research and innovation programme under grant agreement no 763989 (APOLO project). F.D.R. and T.M.W. would like to acknowledge the support from the Engineering and Physical Sciences Research Council (EPSRC) through the SPECIFIC Innovation and Knowledge Centre (EP/N020863/1) and express their gratitude to the Welsh Government for their support of the Ser Solar programme. P.A.T. acknowledges financial support from the Russian Science Foundation (project No. 19-73-30020). J.K. acknowledges the support by the Solar Photovoltaic Academic Research Consortium II (SPARC II) project, gratefully funded by WEFO. M.K.N. acknowledges financial support from Innosuisse project 25590.1 PFNM-NM, Solaronix, Aubonne, Switzerland. C.-Q.M. would like to acknowledge The Bureau of International Cooperation of Chinese Academy of Sciences for the support of ISOS11 and the Ministry of Science and Technology of China for the financial support (no. 2016YFA0200700). N.G.P. acknowledges financial support from the National Research Foundation of Korea (NRF) grants funded by the Ministry of Science, ICT Future Planning (MSIP) of Korea under contracts NRF-2012M3A6A7054861 and NRF-2014M3A6A7060583 (Global Frontier R\&D Program on Center for Multiscale Energy System). CSIRO's contribution to this work was conducted with funding support from the Australian Renewable Energy Agency (ARENA) through its Advancing Renewables Program. A.F.N gratefully acknowledges support from FAPESP (Grant 2017/11986-5) and Shell and the strategic importance of the support given by ANP (Brazil's National Oil, Natural Gas and Biofuels Agency) through the R\&D levy regulation. Y.-L.L. and Q.B. acknowledge support from the National Science Foundation Division of Civil, Mechanical and Manufacturing Innovation under award no. 1824674. S.D.S. acknowledges the European Research Council (ERC) under the European Union's Horizon 2020 research and innovation programme (HYPERION, grant agreement no. 756962), and the Royal Society and Tata Group (UF150033). The work at the National Renewable Energy Laboratory was supported by the US Department of Energy (DOE) under contract 
DE-AC36-08GO28308 with Alliance for Sustainable Energy LLC, the manager and operator of the National Renewable Energy Laboratory. The authors (J.J.B, J.M.L., M.O.R, K.Z.) acknowledge support from the 'De-risking halide perovskite solar cells' program of the National Center for Photovoltaics, funded by the US Department of Energy, Office of Energy Efficiency and Renewable Energy, Solar Energy Technology Office. The views expressed in the article do not necessarily represent the views of the DOE or the US Government. H.J.S. acknowledges the support of EPSRC UK, Engineering and Physical Sciences Research Council. V.T. and M.Madsen acknowledge 'Villum Foundation' for funding of the project CompliantPV, under project no. 13365. M.Madsen acknowledges Danmarks Frie Forskningsfond, DFF FTP for funding of the project React-PV, no. 8022-00389B. M.G. and S.M.Z. thank the King Abdulaziz City for Science and technology (KACST) for financial support. S.V. acknowledges TKI-UE/ Ministry of Economic Affairs for financial support of the TKI-UE toeslag project POP-ART (no. 1621103). RC thanks the grants for Development of New Faculty Staff, Ratchadaphiseksomphot Endowment Fund. A.D.C. gratefully acknowledges funding from the European Union's Horizon 2020 Research and Innovation Program (grant agreement no. 785219-GrapheneCore2 and no. 764047-ESPResSo). M.L.C. and H.X. acknowledges the support from Spanish MINECO for the grant GraPErOs (ENE201679282-C5-2-R), the OrgEnergy Excellence Network CTQ2016-81911- REDT, the Agència de Gestiód'Ajuts Universitaris i de Recerca (AGAUR) for the support to the consolidated Catalonia research group 2017 SGR 329 and the Xarxa de Referència en Materials Avançats per a l'Energia (Xarmae). ICN2 is supported by the Severo Ochoa program from Spanish MINECO (Grant no. SEV-2017-0706) and is funded by the CERCA Programme/Generalitat de Catalunya.

\section{Competing interests}

S.D.S. is a co-founder of Swift Solar Inc; H.J.S. is a co-founder and CSO of Oxford PV Ltd.; A.H. is a co-founder of Dyenamo; M.D. is an employee of Saule Tech; K.D. is an employee at Fluxim AG.

\section{Additional information}

Supplementary information is available for this paper at https://doi.org/10.1038/ s41560-019-0529-5.

Correspondence and requests for materials should be addressed to E.A.K. or M.L.-C. Reprints and permissions information is available at www.nature.com/reprints.

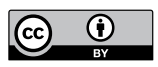

Open Access This article is licensed under a Creative Commons

Attribution 4.0 International License, which permits use, sharing, adaptation, distribution and reproduction in any medium or format, as long as you give appropriate credit to the original author(s) and the source, provide a link to the Creative Commons license, and indicate if changes were made. The images or other third party material in this article are included in the article's Creative Commons license, unless indicated otherwise in a credit line to the material. If material is not included in the article's Creative Commons license and your intended use is not permitted by statutory regulation or exceeds the permitted use, you will need to obtain permission directly from the copyright holder. To view a copy of this license, visit http://creativecommons. org/licenses/by/4.0/.

(c) The Author(s) 2020

'Department of Solar Energy and Environmental Physics, Swiss Institute for Dryland Environmental and Energy Research, J. Blaustein Institutes for Desert Research, Ben-Gurion University of the Negev, Midreshet Ben-Gurion, Israel. ${ }^{2}$ Helmholtz-Zentrum Berlin für Materialien und Energie GmbH, PVcomB, Berlin, Germany. ${ }^{3}$ Ise Katz Institute for Nanoscale Science and Technology, Ben-Gurion University of the Negev, Be'er- Sheva, Israel. ${ }^{4} H e l m h o l t z-Z e n t r u m$ Berlin für Materialien und Energie GmbH, Berlin, Germany. ${ }^{5}$ European Commission, Joint Research Centre (JRC), Ispra, Italy. ${ }^{6}$ National Renewable Energy Laboratory, Golden, CO, USA. 'Department of Materials Science and Engineering, Friedrich Alexander University Erlangen Nürnberg, Erlangen, Germany. ${ }^{8} \mathrm{Helmholtz}$ Institute Erlangen-Nürnberg (HI-ErN), Forschungszentrum Jülich (FZJ), Erlangen, Germany. ${ }^{9} \mathrm{CHOSE}$ (Centre for Hybrid and Organic Solar Energy), Department of Electronic Engineering, University of Rome Tor Vergata, Rome, Italy. ${ }^{10}$ Department of Electrical Engineering and Computer Science, Massachusetts Institute of Technology, Cambridge, MA, USA. "Andlinger Center for Energy \& The Environment, Princeton University, Princeton, NJ, USA. ${ }^{12}$ Metallurgy and Materials Science Research Institute, Chulalongkorn University, Bangkok, Thailand. ${ }^{13}$ State Key Laboratory of Advanced Technology for Materials Synthesis and Processing, Wuhan University of Technology, Wuhan, China. ${ }^{14}$ Light Technology Institute, Karlsruhe Institute of Technology (KIT), Karlsruhe, Germany. ${ }^{15}$ University of Grenoble Alpes, CEA, LITEN, INES, Le Bourget du Lac, France. ${ }^{16}$ Fluxim AG, Winterthur, Switzerland. ${ }^{17}$ Saule Technologies, Wroclaw Technology Park, Wroclaw, Poland. ${ }^{18} \mathrm{CSIRO}$ Energy, Mayfield West, New South Wales, Australia. ${ }^{19}$ Department of Electrical Engineering and Computer Science, University of Michigan, Ann Arbor, MI, USA. ${ }^{20}$ Department of Physics, University of Michigan, Ann Arbor, MI, USA ${ }^{21}$ Department of Materials Science and Engineering, University of Michigan, Ann Arbor, MI, USA. ${ }^{22}$ TNO - Solliance, High Tech Campus, Eindhoven, The Netherlands. ${ }^{23}$ Department of Chemistry, University of Rome La Sapienza, Rome, Italy. ${ }^{24}$ Laboratory for Photonics and Interfaces, Institute of Chemical Sciences and Engineering, École Polytechnique Fédérale de Lausanne, Lausanne, Switzerland. ${ }^{25}$ Laboratory of Photomolecular Science, Institute of Chemical Sciences and Engineering, École Polytechnique Fédérale de Lausanne, Lausanne, Switzerland. ${ }^{26}$ Department of Physics and Astronomy, Vrije Universiteit Amsterdam, Amsterdam, The Netherlands. ${ }^{27}$ Center for Energy and Environmental Chemistry Jena (CEEC Jena), Friedrich Schiller University Jena, Jena, Germany. ${ }^{28}$ School of Electronic Engineering, Bangor University, Bangor, Gwynedd, Wales, UK. ${ }^{29}$ Department of Materials Science and Engineering, Institute for Research in Electronics and Applied Physics, University of Maryland, College Park, MD, USA. ${ }^{30}$ Department of Materials Science and Engineering, University of California, Davis, CA, USA. ${ }^{31}$ Dalian National Laboratory for Clean Energy/Dalian Institute of Chemical Physics, Chinese Academy of Sciences, Dalian, Liaoning, Shaanxi, China. ${ }^{32}$ Key Laboratory for Advanced Energy Devices; Shaanxi Engineering Lab for Advanced Energy Technology; Institute for Advanced Energy Materials; School of Materials Science and Engineering, Shaanxi Normal University, Xi'an, Shaanxi, China. ${ }^{33}$ Department of Chemical and Biological Engineering, Princeton University, Princeton, NJ, USA. ${ }^{34}$ Printable Electronics Research Center, Suzhou Institute of Nano-Tech and Nano-Bionics, Chinese Academy of Sciences (CAS), Suzhou, China. ${ }^{5}$ SDU NanoSYD, Mads Clausen Institute, University of Southern Denmark, Sønderborg, Denmark. ${ }^{36}$ University of Colorado Boulder, Boulder, Colorado, USA. ${ }^{37}$ Group for Molecular Engineering of Functional Materials, Institute of Chemical Sciences and Engineering, École Polytechnique Fédérale de Lausanne, Sion, Switzerland. ${ }^{38}$ Laboratório de Nanotecnologia e Energia Solar, Chemistry Institute, University of Campinas - UNICAMP, Campinas, São Paulo, Brazil. ${ }^{39}$ Department of Chemical Engineering, Boğaziçi University, Bebek, Istanbul, Turkey. ${ }^{40}$ School of Chemical Engineering, Sungkyunkwan University (SKKU), Suwon, Korea. ${ }^{4}$ SPECIFIC, College of Engineering, Swansea University, Bay Campus, Swansea, UK. ${ }^{42}$ Institute of Materials Science, Technical University of Darmstadt, Darmstadt, Germany. ${ }^{43}$ IEK-5 Photovoltaik, Forschungszentrum Jülich $\mathrm{GmbH}$, Jülich, Germany. ${ }^{44}$ Laboratory of Organic and Macromolecular Chemistry (IOMC), Friedrich Schiller University Jena, Jena, Germany. ${ }^{45}$ Clarendon Laboratory, University of Oxford, Oxford, UK. ${ }^{46}$ Cavendish Laboratory, University of Cambridge, Cambridge, UK. ${ }^{47}$ Skolkovo Institute of Science and Technology, Moscow, Russia. ${ }^{48}$ IPCP RAS, Chernogolovka, Russia. ${ }^{49}$ Department of Materials, Imperial College London, London, UK. ${ }^{50}$ Department of Materials Science and Engineering, Yonsei University, Seoul, Korea. ${ }^{51}$ Catalan Institute of Nanoscience and Nanotechnology (ICN2), CSIC and The Barcelona Institute of Science and Technology, Bellaterra, Barcelona, Spain. *e-mail: keugene@bgu.ac.il; monica.lira@icn2.cat 